\title{
7. Cardiología intervencionista
}

\subsection{Implante percutáneo de válvula aórtica en situación de emergencia}

Zaragoza Cortés Carlos Alberto, Gutiérrez Hernández Karol Gemma, Díez Macía Juan Ramón, Viveros Rentería Eduardo,

Kiamco Castillo César Ricardo, Álvarez Mosquera José Benito Hospital Español.

Tipo de estudio: Reporte de casos clínicos con revisión de fuentes

Introducción: La estenosis aórtica es la enfermedad valvular con mayor prevalencia a nivel mundial. Su diagnóstico y tratamiento oportuno es determinante en la supervivencia. El implante percutáneo de válvula aórtica (TAVI) tiene indicaciones ya establecidas. Su colocación en situación de emergencia podría ser una opción viable para aquellos pacientes que se presentan con una descompensación aguda que pone en riesgo su vida; en cuanto a desenlace es equiparable a las opciones terapéuticas actuales. Descripción del caso: Masculino de 82 años. Múltiples antecedentes cardiovasculares. Estenosis aórtica severa diagnosticada dos años previos. Internamientos previos por insuficiencia cardiaca descompensada. Acude por presentar nuevo episodio de insuficiencia cardiaca descompensada con dolor torácico, edema pulmonar y posteriormente choque cardiogénico. Durante su internamiento requiere revascularización coronaria percutánea. Presenta deterioro clínico que requiere implantación percutánea de válvula aórtica de emergencia. Metodología: Se realiza búsqueda en PubMed con los siguientes términos: tratamiento estenosis aórtica severa, implante percutáneo de válvula aórtica en situación de urgencia o emergencia, choque cardiogénico en estenosis aórtica severa, revascularización coronaria en estenosis aórtica severa, valvuloplastia con balón en estenosis aórtica severa descompensada. Resultados: El implante de TAVI de emergencia está descrito en estudios retrospectivos con cohortes pequeñas. Se observa un desenlace favorecedor en estos pacientes, siendo superior a las opciones terapéuticas actuales. El momento para realizar revascularización coronaria percutánea es controversial. Es nuestra intención dar a conocer el caso y la evolución de un paciente con todas estas características y así contribuir con el conocimiento acerca de este escenario clínico. Discusión: El implante valvular aórtico percutáneo es una opción terapéutica en pacientes de alto riesgo quirúrgico. Se estudia la posibilidad de ser utilizado en pacientes con otra categoría de riesgo. Su colocación en situación de urgencia y emergencia está descrita en estudios retrospectivos con cohortes pequeñas. El desenlace podría ser superior a las opciones terapéuticas actuales como la valvuloplastia con balón.

\subsection{Score TIMI y GRACE alto como predictor para enfermedad trivascular en pacientes con angina inestable}

Esparza Rafael, Cortés Aguirre Mauricio, Salas Delgado Arnoldo, Valadez Molina Francisco Javier, Reyna Reyna Enrique Hospital Regional Monterrey ISSSTE.

Tipo de estudio: Estudio pronóstico

Introducción: La identificación de factores de riesgo en pacientes con enfermedad coronaria permite una adecuada estratificación para un seguimiento y tratamiento más agresivos. Existen diferentes puntajes de predicción de riesgo en el SICA, entre ellos se encuentran el Thrombolysis In Myocardial Infarction (TIMI) y el Global Registry for Acute Coronary Events (GRACE). La presencia de enfermedad multivaso es importante, ya que en ocasiones el tratamiento es quirúrgico. Objetivo: Determinar si la escala TIMI y Grace score son un factor de riesgo de enfermedad trivascular, previo a un estudio diagnóstico más específico e invasivo. Metodología: Estudio observacional, transversal y retrospectivo. Se identificaron pacientes mayores de 18 años con diagnóstico de angina inestable y enfermedad trivascular que contaran con score TIMI y Grace, ingresados al Servicio de Medicina Interna. Se dividieron en dos grupos: el primero de 27 pacientes con enfermedad trivascular y TIMI/Grace score de moderado a alto riesgo, de estos 20 fueron hombres. Resultados: Siete mujeres de edad media de 63.3 años. El grupo control contó con 28 pacientes, 16 hombres y 12 mujeres, obteniendo una media de edad de 63.9 años. Se utilizó análisis estadístico mediante $\chi^{2}$ para obtener un valor $p$ y odds ratio (OR) para obtener el factor de riesgo entre TIMI y Grace score con enfermedad trivascular. Discusión y conclusiones: Por el contrario, en nuestro estudio encontramos que la elevación de estas escalas de mortalidad no son un factor de riesgo para padecer enfermedad de tres vasos.

\subsection{Infarto agudo al miocardio sin elevación del segimento ST (IAMSEST) con bloqueo trifascicular}

Hernández Torres Abishnaed Eileen, García Jiménez Yoloxóchitl, Soto González Juan Ignacio

UMAE Hospital de Especialidades No. 14, Veracruz.

Tipo de estudio: Reporte de casos clínicos con revisión de fuentes

Introducción: El bloqueo cardiaco trifascicular resulta de la presencia de bloqueo bifascicular más bloqueo AV de primer grado. La etiología principal es por enfermedad coronaria e hipertensión; su expresión se asocia con una mortalidad hasta de $47 \%$ en eventos isquémicos agudos. Descripción del caso: Masculino de 68 años, hipertenso, diabético, angina estable. Presenta angina de 60 minutos de evolución y datos de falla cardiaca. El electrocardiograma muestra bloqueo AV de primer grado, bloqueo fascicular anterior y bloqueo completo de rama derecha, Tnl positiva. Diagnóstico: infarto agudo al miocardio sin elevación del segmento ST (IAMSEST). Cateterismo: DA lesión significativa proximal y media con disección, colocación de dos stents exitosos. Evolución favorable y reversión del triple bloqueo. Metodología: En la búsqueda bibliográfica de revistas indexadas en PubMed se encontró que la presencia de bloqueo trifascicular se asocia en $10 \%$ de los casos con infarto agudo al miocardio con elevación del ST (IAMCEST). En el IAMSEST no hay estudios que estimen su prevalencia, aunque se asocia con un peor pronóstico. Resultados: No se ha documentado el pronóstico de la relación del bloqueo trifascicular y el IAMSEST. Sin embargo, en el IAMCEST se ha descrito una mortalidad hasta de $47 \%$, de ahí la relevancia de un diagnóstico oportuno cuando se encuentran estas alteraciones y no se observan los datos clásicos electrocardiográficos de isquemia y lesión (onda T y segmento ST). Discusión: La evaluación integral del cuadro 
Figura 7.3.1:

A) Electrocardiograma en una paciente con IAMSEST y bloqueo trifascicular. B) Electrocardiograma 12 horas posteriores al intervencionismo coronario exitoso en la descendente anterior con reversión del triple bloqueo.
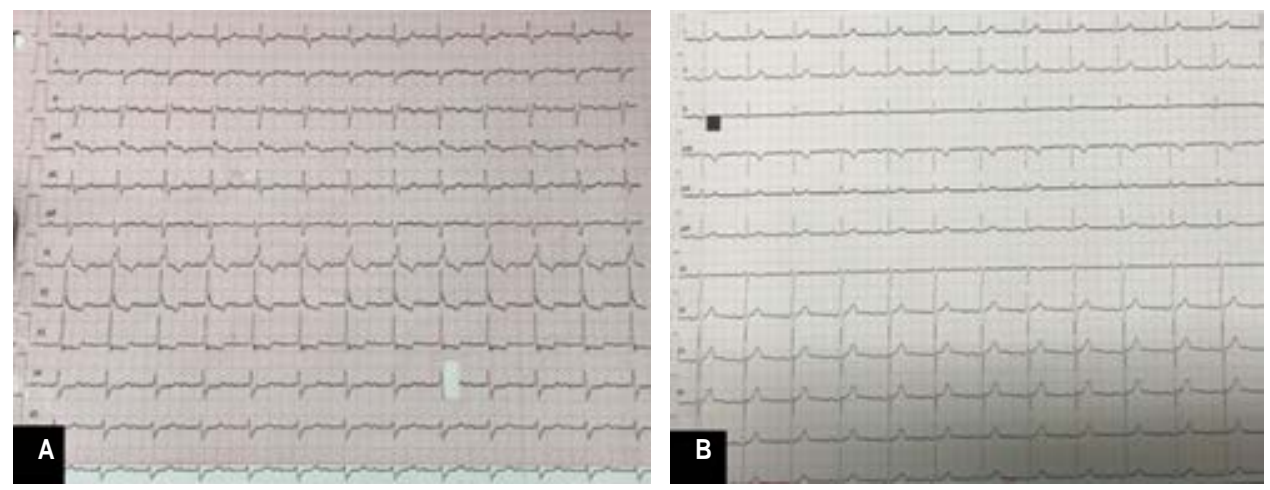
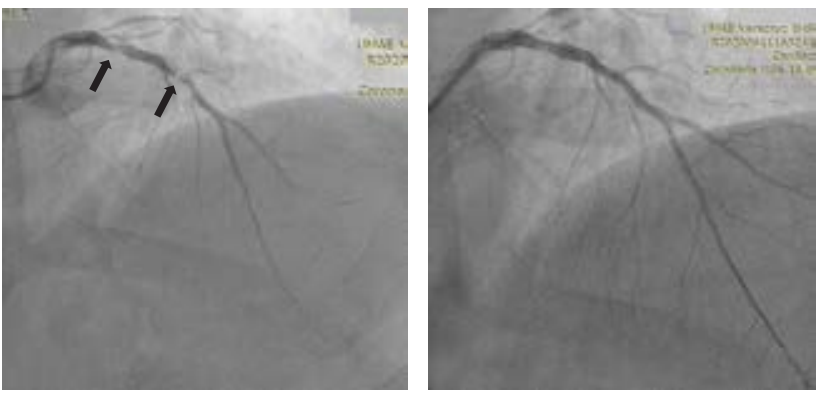

Figura 7.3.2: Angiografía coronaria en paciente con IAMSEST y bloqueo trifascicular. A) Lesión significativa proximal y en segmento medio con disección (flecha). B) Postcolocación de stent proximal y medio con flujo TIMI III.

clínico y la Tnl elevada permitió definir el diagnóstico del paciente. La oclusión de la ADA se asocia al triple bloqueo, puesto que la rama derecha del haz de His y el fascículo anterior de la rama izquierda reciben irrigación de las septales de esta arteria. La intervención temprana modificó el pronóstico del paciente satisfactoriamente.

\subsection{Comunicación interauricular resuelta por cierre percutáneo}

Palomares Vega Froylan,* Leyva Velarde Heriberto, ${ }^{\ddagger}$

Lupercio Mora Karina, ${ }^{\ddagger}$ Saturno Chiu Karina, ${ }^{\ddagger}$ Almeida Gutiérrez Eduardo ${ }^{\ddagger}$ * Instituto Mexicano del Seguro Social. ${ }^{\star}$ Hospital de Cardiología del Centro Médico Nacional Siglo XXI, IMSS.

Tipo de estudio: Reporte de casos clínicos con revisión de fuentes

Introducción: La comunicación interauricular (CIA) es una enfermedad relativamente benigna, pero sin tratamiento evoluciona a sobrecarga derecha, falla cardiaca, hipertensión pulmonar, embolismo sistémico y arritmias. Históricamente el cierre era mediante técnica quirúrgica (el primero en 1939), en 1974 se describe el cierre percutáneo, en la actualidad, ésta es una alternativa eficaz y segura, con más de $80 \%$ de tasa de éxito. Descripción del caso: Hombre de 54 años, antecedente de hipertensión arterial sistémica y diabetes tipo 2. Comienza con disnea progresiva al reposo. Se ausculta soplo expulsivo, foco pulmonar II/VI, con desdoblamiento fijo del 2P. El ecocardiograma muestra CIA ostium secundum de $7.9 \times 15 \mathrm{~mm}$, borde anterosuperior y anterior $15 \mathrm{~mm}$, posterosuperior $7 \mathrm{~mm}$, posterior $14 \mathrm{~mm}$, Qp:Qs
1.6:1, sin HAP. Se realizó cierre exitoso: dispositivo Figulla Flex-II 21 $\mathrm{mm}$, sin complicaciones. Metodología: A través del método booleano se realizó búsqueda de términos $\mathrm{MeSH}$ «interatrial communication» [and] «treatment» en las bases de datos con repositorios de evidencia científica arbitrada indizada (PubMed) y no indizadas (Google Scholar). Resultados: El cierre percutáneo es el tratamiento de elección, ya que al compararlo con el cierre quirúrgico muestra menos complicaciones (7 vs 24\%). El dispositivo Amplatzer-Septal-Occluder (ASO) es el más utilizado; el Figulla Flex-II-ASD Occluder tiene una mejor tasa de éxito (98 vs 95\%) sin casos reportados de erosión tardía y con disminución en arritmias, radiación y cortocircuito residual postquirúrgico inmediato. Discusión: El cierre percutáneo en CIA es un procedimiento eficaz y seguro, muestra una tasa de éxito de $90-100 \%$ y una tasa de complicaciones baja, siendo la más documentada la fibrilación auricular en $4.4 \%$. Existe riesgo a largo plazo de cortocircuito residual y arritmias cardiacas, por lo cual se enfatiza en la importancia de la técnica y el dispositivo.

\subsection{IAMCEST en nacimiento anómalo de coronaria izquierda y taquicardia supraventricular, en COVID-19}

García Jiménez Yoloxóchitl, González Moreno Jesús, Soto González Juan Ignacio

UMAE Hospital de Especialidades No. 14, Veracruz.

Tipo de estudio: Reporte de casos clínicos con revisión de fuentes

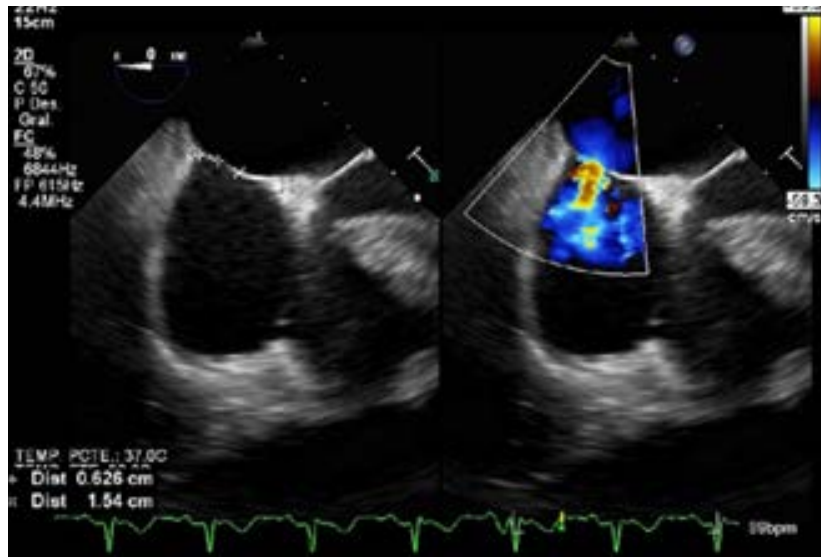

Figura 7.4.1. 

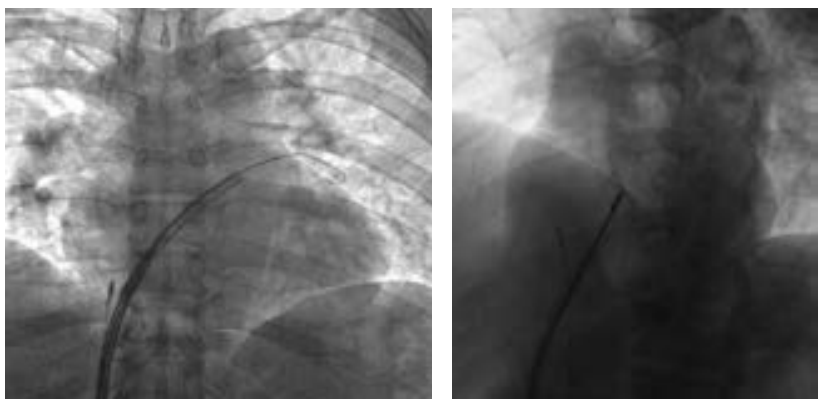

Figura 7.4.2.

Introducción: La infección por SARS-CoV-2 ocasiona el síndrome COVID-19 caracterizado por un estado inflamatorio marcado en los casos más graves. Se han identificado diferentes manifestaciones cardiovasculares secundarias por daño directo e indirecto por inflamación e hipoxia. La presencia de hipertensión, diabetes y obesidad incrementan la mortalidad por la alteración en la expresión del receptor de la ECA2 que funge como receptor viral. Descripción del caso: Masculino de 45 años, diabético, hipertenso, obeso. Presenta angina. Diagnóstico IAMCEST lateral alto. Angiografía: TCl con origen del ostium de la CD, oclusión de la Cx. Se coloca stent; 24 horas después presenta fiebre y desaturación, por lo que requiere ventilación mecánica. TAC pulmonar: CO-RADS4. RT-PCR negativa. Tratamiento con antimicrobianos. Ecocardiograma: FEVI 25\%. Veinte días después reingresa por taquicardia supraventricular (TSV), recibió amiodarona y ajuste de betabloqueador. Metodología: Se realiza una revisión sistemática y exhaustiva de todos los artículos indexados a junio de 2020, disponibles en la base de datos de PubMed-Medline y Science Direct implementando las palabras clave: cardiovascular disease and COVID-19, coronary syndrome and COVID-19, acute myocardial infarction and COVID-19, arrhythmias and COVID, anomalous left main, dando relevancia al factor de impacto. Resultados: La RTPCR puede tener falsos negativos (S70\%, E95\%). Una probabilidad pretest del $90 \%$ con prueba negativa disminuye la probabilidad a $74 \%$. La TSV es infrecuente 72 horas posterior al IAMCEST. Ambos se han asociado con COVID-19. El origen anómalo del TCI tiene una incidencia de $0.15 \%$. Se desconoce si predispone a ateroesclerosis o TSV, aunque se asocia con muerte súbita. Discusión: Los factores de riesgo cardiovascular son condicionantes de eventos isquémicos y arritmias. La relevancia del nacimiento anómalo del TCI para estos no se puede definir. El IAMCEST y la TSV pueden ser manifestaciones de COVID-19. En la actualidad, es difícil determinar el papel específico del SARS-CoV-2 sobre los eventos cardiovasculares agudos en presencia de comorbilidades y clínica compatible, pero con PCR negativa.
Figura 7.5.1:

A) Angiografía coronaria con nacimiento anómalo de la arteria coronaria izquierda a partir del ostium de la coronaria derecha (CD). Se bifurca en descendente anterior (DA) y circunfleja (Cx), se observa oclusión proximal aguda de la $\mathrm{Cx}$. B) Se colocó stent Promus Premier de $3.5 \times$ $20 \mathrm{~mm}$ a la Cx (flecha), exitoso.
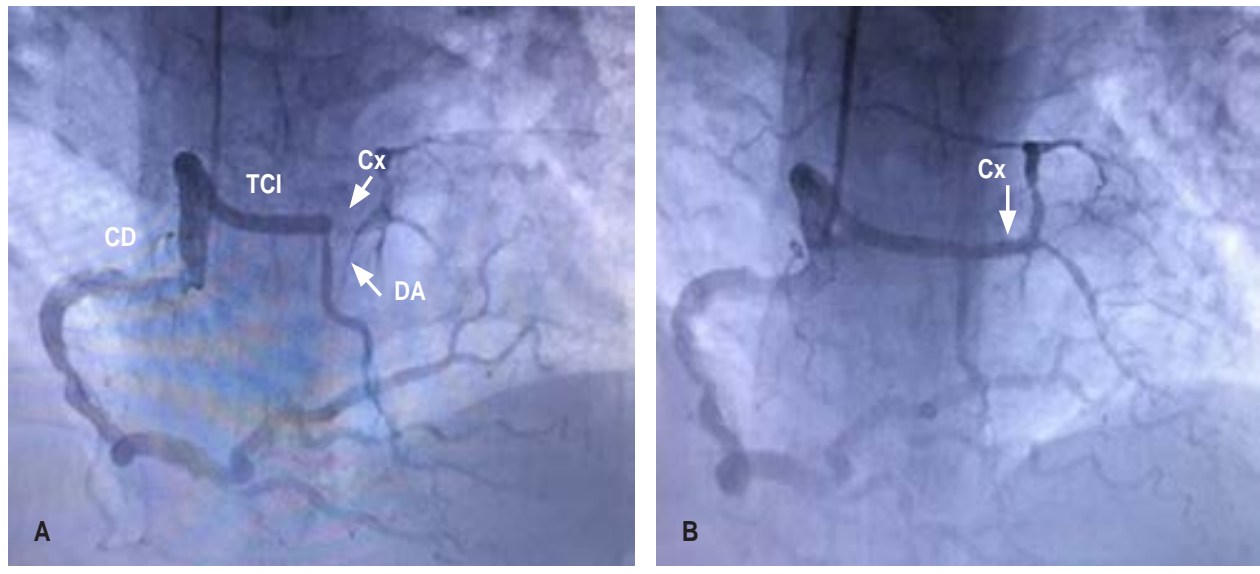
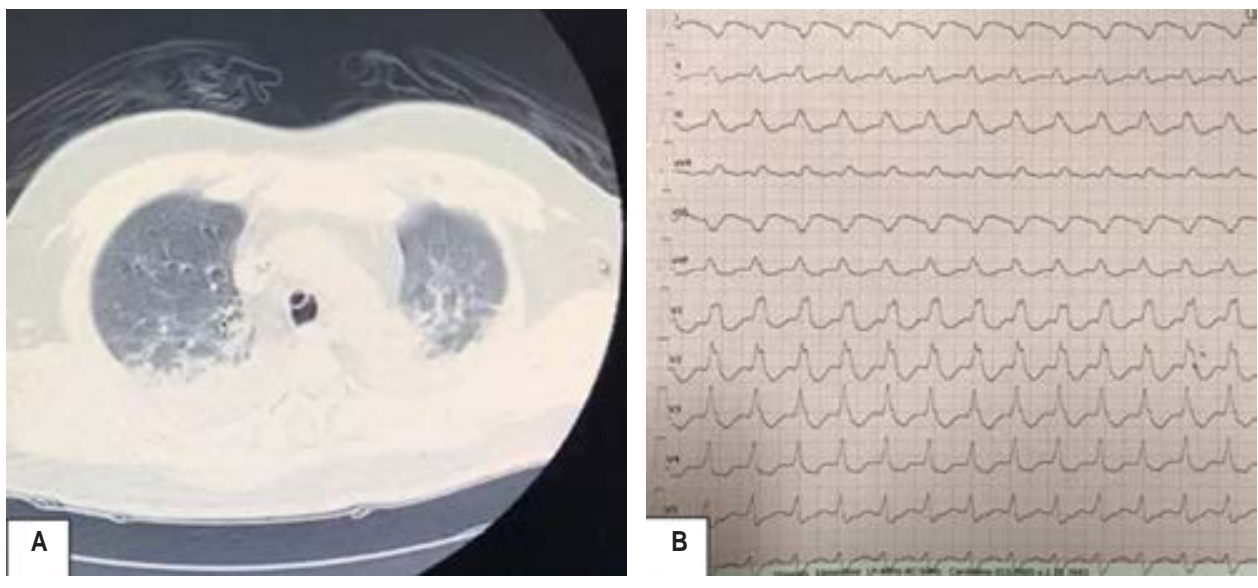

\section{Figura 7.5.2:}

A) Tomografía axial

computarizada de tórax realizada a las 14 horas del IAMCEST, catalogada como CO-RADS 4. B) Electrocardiograma realizado a los 20 días del IAMCEST lateral alto, se observa taquicardia supraventricular con morfología de bloqueo de rama derecha. 


\subsection{Costo efectividad del tratamiento con implante valvular aórtico transcatéter versus cirugía valvular}

Martínez Jaimes Tomás de Jesús, García Méndez Rosalba Carolina Hospital de Cardiología del Centro Médico Nacional Siglo XXI, IMSS. Tipo de estudio: Registros locales o nacionales

Introducción: La evaluación del impacto económico de la adopción de nuevos procedimientos de intervención en la práctica clínica, así como la costo-efectividad de dos estrategias de reemplazo valvular aórtico en el mundo real, tomando en cuenta los días de estancia intrahospitalaria, recuperación y posibles complicaciones asociadas, resulta trascendente para las instituciones de salud pública. Objetivo: Comparar la costo-efectividad del tratamiento con TAVR vs SAVR en pacientes con estenosis aórtica severa sintomática de riesgo intermedio y alto en la UMAE Hospital de Cardiología del CMN SXXI. Metodología: Se realizó una evaluación económica completa de tipo costo-efectividad en pacientes sometidos a implante valvular aórtico transcatéter o cirugía valvular aórtica de enero de 2015 a mayo de 2018. Se analizaron los costos directos, días promedio de estancia, complicaciones intrahospitalarias asociadas, así como la razón de costo-efectividad incremental. Resultados: Los pacientes del grupo TAVR tuvieron un tiempo total de cinco (4-6) días de estancia y de 11 (9.5-13) días en SAVR, $\mathrm{p} \leq$ 0.0001. El valor puntual de la razón de costo-efectividad incremental fue de $\$ 36,675.00$ por cada 13 puntos porcentuales de pacientes no complicados. Discusión y conclusiones: El procedimiento de TAVR tiene un costo más alto que SAVR (2.3 veces mayor), tiene mayor efectividad que SAVR, pero no es más costo-efectivo.

\section{Trabajo ganador del premio Dr. Carlos Pérez Treviño Segundo Lugar}

\subsection{Catéter único en coronariografía diagnóstica transradial: ¿catéter TIG o JL?}

López López Fernando, Beltrán Nevárez Octavio, Castro Ramírez Gildardo, Triano Doroteo José Luis, Ríos Corral Marco Antonio, Córdova Leyva Luis Armando, Hernández Mejía Rogelio Centro Cardiovascular de Culiacán.

Tipo de estudio: Registros locales o nacionales
Introducción: Las guías actuales favorecen el uso de la vía transradial en angiografía diagnóstica coronaria. El unicatéter contra múltiples catéteres es uno de los principales temas de controversia cuando el espasmo vascular es uno de los factores del fracaso en el acceso radial. Además, el uso de catéteres de mayor tamaño, catéteres adicionales y la manipulación son factores adicionales al fracaso. Objetivo: Dar a conocer las ventajas competitivas individuales del uso de cada uno de los catéteres mencionados en coronariografía diagnóstica por vía radial. Metodología: Se evaluaron 2,117 casos. Se analizó el tipo de catéter, la conversión a multicatéter, éxito del procedimiento, fluoroscopia, medio de contraste, exposición a Kerma aéreo, espasmo radial y costo total. Todos los procedimientos fueron realizados por cardiólogos intervencionistas con más de 500 procedimientos de experiencia cada uno. La elección del catéter fue hecha a discreción del propio intervencionista. Resultados: 41.1\% utilizaron JL y 58.9\% TIG. Conversión: 71\% JL conversión a JR 68\%, 29\% TIG conversión a JL 45\%. Éxito: 97\% JL y 95\% TIG. Fluoroscopia: TIG $4.07 \pm 2.08$ y JL $5.66 \pm 1.34$ minutos. Medio de contraste: TIG $75.81 \pm 25$, JL $84.23 \pm 16 \mathrm{~mL}$. Kerma aéreo: $1,176.09 \pm 88.03$ mGy TIG y 1,698.33 \pm 56.15 mGy JL. Espasmos: $55.6 \%$ TIG y $44.4 \%$ JL. Costo TIG: 1,490 pesos, JL: 550 pesos, JR: 490 pesos. Discusión y conclusiones: El catéter JL permite gran porcentaje con éxito y menores complicaciones. Gran beneficio utilizando JL, incluso en conversión a JR adicional el costo es similar a usar TIG como unicatéter.

\subsection{Complicaciones y hallazgos a largo plazo de ecocardiografía de estrés con dobutamina}

López López Fernando, Beltrán Nevárez Octavio,

Castro Ramírez Gildardo, Triano Doroteo José Luis, Ríos Corral Marco Antonio, Córdova Leyva Luis Armando, Hernández Mejía Rogelio

Centro Cardiovascular de Culiacán.

Tipo de estudio: Registros locales o nacionales

Introducción: El ecocardiograma de estrés con dobutamina, o generalmente conocido como eco-dobutamina, es de amplio uso entre la comunidad cardiológica para la valoración de viabilidad miocárdica además de la isquemia en todos aquellos sujetos en quienes se tenga la sospecha y principalmente la certeza de enfermedad arterial coronaria. Objetivo: Describir los hallazgos y

Tabla 7.7.1: Nuestra experiencia en coronariografía diagnóstica transradial.

Variables

Total de casos

Conversión > 1 catéter

Éxito procedimiento (\%)

Tiempo fluoroscopia (min)

Medio de contraste (mL)

Kerma aéreo (mGy)

Espasmo radial

Costo económico un catéter

Costo económico multicatéter

Costo comparativo acumulado para 100 pacientes

Diferencia
TIG

1,247

29\% (catéter JL 45\%)

95

$4.07 \pm 2.18$

$75.81 \pm 25.00$

$1,176.09 \pm 88.03$

15

$\$ 1,490.00$

$\$ 2,040.00$

Cat. único: \$ 149,000.00

Multi cat: $\$ 204,000.00$

Cat. único: \$ 94,000.00 a favor de catéter JL (63\%)

\section{JL}

870

$71 \%$ (catéter JR 68\%)

97

$5.66 \pm 3.34$

$84.23 \pm 16.00$

$1,698.33 \pm 56.15$

12

$\$ 550.00$

$\$ 1,040.00$

Cat. único: $\$ 55,000.00$

Multi cat: $\$ 104,000.00$

Multi cat: \$ 100,000.00 a favor de catéter JL (49\%) 
Tabla 7.8.1: Ecocardiografía de estrés con dobutamina.

- 122 casos totales de estrés con dobutamina

- Sexo: 62 femenino, 60 masculino

- Edad promedio: 66.1 años

- 58 casos negativos para isquemia

- 19 casos positivos para isquemia

- Cinco casos viabilidad miocárdica sin isquemia

- Seis casos sugestivos de isquemia

- Ocho casos no concluyentes por emergencia hipertensiva

- Tres casos presentaron dolor torácico inespecífico durante la prueba

complicaciones encontrados en los pacientes que fueron sometidos a ecocardiograma de estrés con dobutamina en nuestro centro cardiovascular. Metodología: Estudio descriptivo, observacional, retrospectivo. Se incluyeron a todos los pacientes del periodo de 2012 a 2018 de nuestro centro cardiovascular en quienes se realizó ecocardiograma de estrés con dobutamina. Se registraron y analizaron los resultados en hallazgos y complicaciones de todos los estudios y además se colectó la información base de todos los pacientes. Resultados: Se realizaron 122 ecocardiogramas de estrés con dobutamina en 60 hombres y 62 mujeres. Promedio de edad: 66.1 años. Cincuenta y ocho negativos para isquemia y 19 positivos. Cinco sujetos presentaron viabilidad sin isquemia, seis casos fueron sugestivos de isquemia y, por último, los no concluyentes fueron ocho (que no alcanzaron la frecuencia máxima deseada por emergencia hipertensiva en todos los casos). Tres pacientes presentaron dolor torácico inespecífico. Discusión y conclusiones: El ecocardiograma por estrés con dobutamina es un estudio diagnóstico que
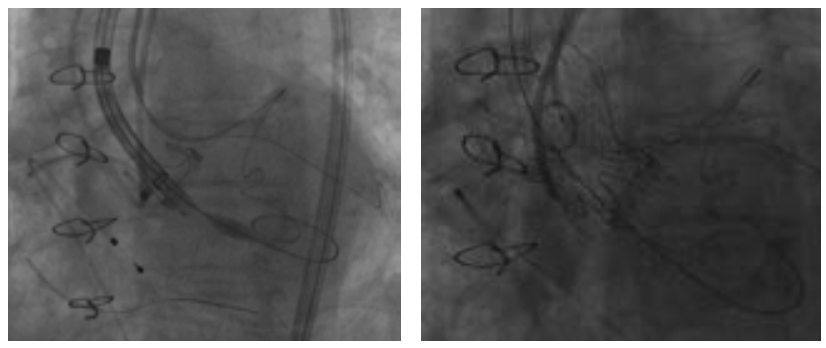

Figura 7.9.1. por lo general tiene pocas contraindicaciones, es accesible para el sujeto y de relativa facilidad para el cardiólogo entrenado.

\subsection{Técnica de chimenea bilateral en implante de prótesis aórtica transcatéter "válvula en válvula"}

Domagala Bibiano Andrzej, Uribe Jhonathan,

González Olvera Jimena Alejandra, Estrada Gallegos Joel

Instituto Mexicano del Seguro Social.

Tipo de estudio: Reporte de casos clínicos con revisión de fuentes

Introducción: La oclusión de arterias coronarias (OAC) es una complicación posible durante el implante de prótesis aórtica transcatéter (TAVI). Aunque es poco común $(<1 \%$ ), la mortalidad puede ser hasta de $100 \%$. Existen grupos de riesgo en los que la incidencia crece, como válvulas bioprotésicas quirúrgicas degeneradas (procedimientos válvula en válvula [VIV] en los que aumenta el riesgo seis veces). Descripción del caso: Paciente femenino de 75 años con implante de prótesis biológica Edwards Magna Perimount 2700 en 2010. Se evidenció degeneración severa protésica (AVAo 0.34 $\mathrm{cm}^{2} /$ Gmed 42 torr). La reintervención quirúrgica fue rechazada al considerarse de alto riesgo. Fue aceptada para implante de TAVI, con procedimiento VIV y protección profiláctica de los ostia coronarios con técnica de chimenea. Metodología: A través del método booleano se realizó búsqueda de términos MeSH «Chimney technique» [and] «valve in valve» en las bases de datos con repositorios de evidencia científica arbitrada indizada (PubMed) y no indizadas (Google Scholar). Resultados: Los pacientes con riesgo de OAC pueden ser tratados con TAVI. En ellos se realiza protección inicial de la arteria colocando guía coronaria, balón o stent no liberado antes del despliegue de TAVI. Si el flujo sanguíneo se compromete durante o después de la expansión de la misma existen dos métodos descritos para su protección. Discusión: Esta técnica llamada «chimenea o snorkel» se describió en procedimientos de reparación de aneurismas endovasculares renales o mesentéricos. La variante coronaria radica en liberar stents hacia la aorta paralelos a la prótesis TAVI. Hasta donde sabemos, este es el primer implante exitoso en México de prótesis transcatéter con técnica de chimenea bilateral en procedimiento VIV.

\subsection{Reparación percutánea endovascular de aneurisma de aorta abdominal (PEVAR) yuxtarrenal}

Diaz García Pedro,* Rodríguez Villareal Alberto, ${ }^{\ddagger}$

Uribe González Jhonathan, ${ }^{\ddagger}$ Montoya Guerrero Silvestre, ${ }^{\ddagger}$

Estrada Gallegos Joel ${ }^{\ddagger}$
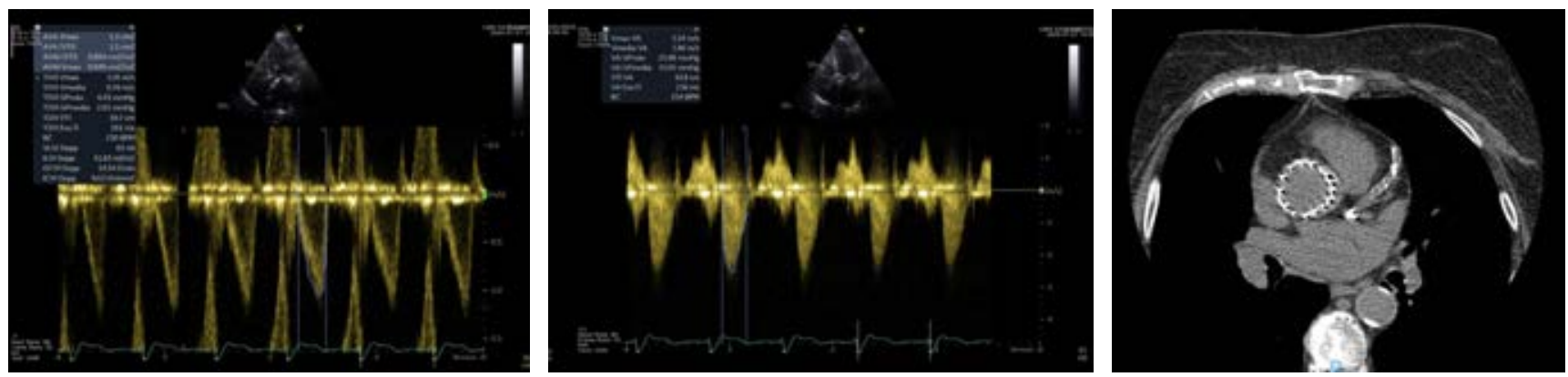

Figura 7.9.2. 
* UMAE Hospital de Cardiología del Centro Médico Nacional Siglo XXI, IMSS. ${ }^{\ddagger}$ Instituto Mexicano del Seguro Social.

Tipo de estudio: Reporte de casos clínicos con revisión de fuentes

Introducción: La reparación endovascular de aneurisma de aorta abdominal (AAA) es un procedimiento menos invasivo que presenta una reducción del tiempo quirúrgico, pérdida sanguínea, menor estancia en cuidados intensivos y hospitalaria, menores complicaciones cardiacas, respiratorias, menor morbilidad y mortalidad temprana que la reparación abierta. Con una mortalidad menor a 30 días comparada con la cirugía. Descripción del caso: Masculino de 67 años, diabético e hipertenso; diagnóstico de AAA, diámetro axial de $8.2 \times 8 \mathrm{~cm}$ y longitud de $14.5 \mathrm{~cm}$. Se colocó endoprótesis Endurant II de $28 \times 16 \times 166 \mathrm{~mm}$ en aorta abdominal con extensión izquierda de $16 \times 13 \times 156 \mathrm{~mm}$ y derecha de $16 \times 20$ $\times 93 \mathrm{~mm}$; stents renales arteriales derecho/izquierdo BE GRAFT de $7 \times 57 \mathrm{~mm}$ y BE GRAFT de $8 \times 57 \mathrm{~mm}$ exitoso. Metodología: Se realizó una búsqueda bibliográfica en bases de datos con repositorios de evidencia científica arbitrada indizada (PubMed) y no indizada (Google Scholar). Resultados: La reparación endovascular sigue siendo considerada una indicación Ila en pacientes con alto riesgo quirúrgico de manera electiva; la técnica de chimenea es una opción terapéutica con indicación lla en todo paciente con aumento de tamaño considerable o alto riesgo de rotura. Discusión: Este caso describe uno de los usos de endoprótesis en patología vascular compleja con alto riesgo quirúrgico. Presentando un impacto importante en la supervivencia, la importancia radica en la poca experiencia en nuestro país con esta técnica, a pesar de las múltiples
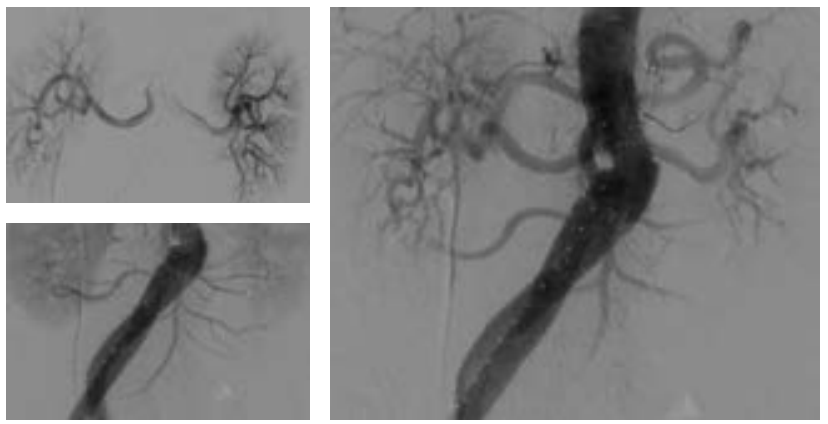

Figura 7.10.1.
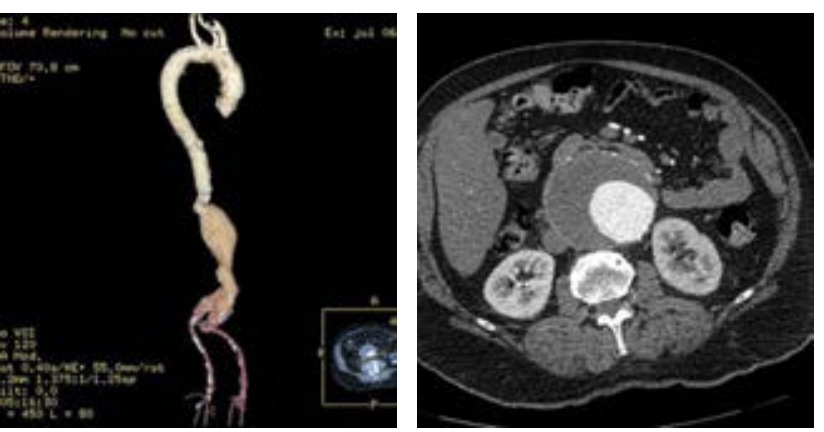

Figura 7.10.2.

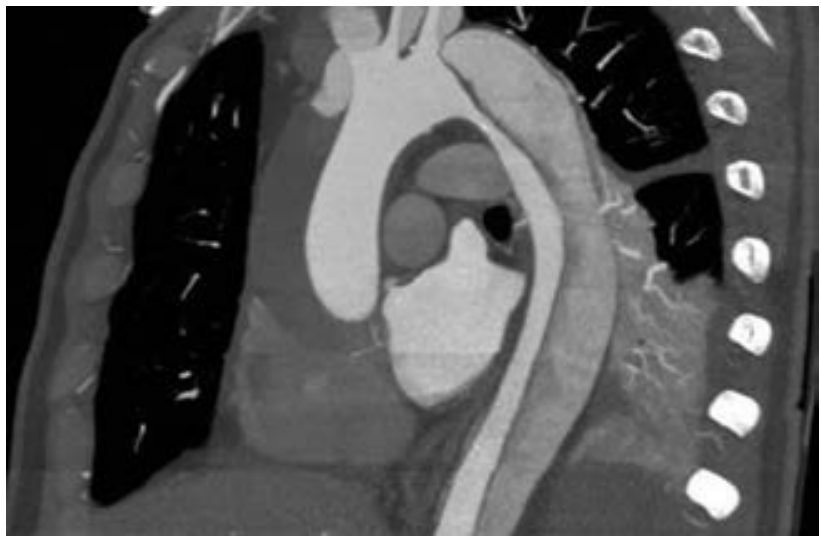

Figura 7.11.1.

Figura 7.11.2.

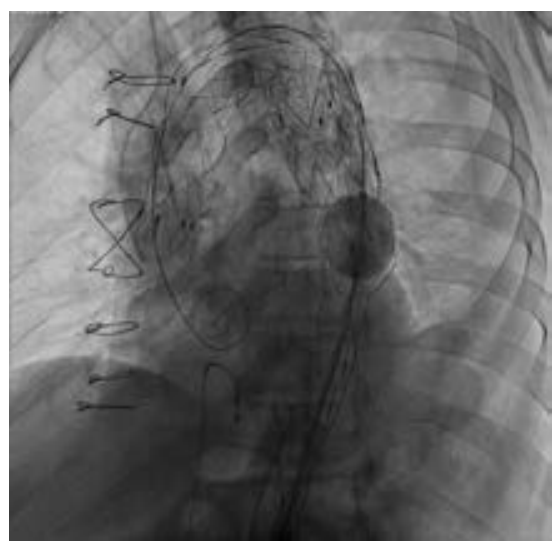

ventajas. Consideramos que esta recomendación podría tener un mayor impacto con el aumento de investigación sobre esta técnica.

\subsection{Tratamiento híbrido de disección aórtica y hematoma intramural Stanford $A$}

Novelo Quijano Pedro Augusto, Pineda Pineda Gabriela Alejandra, Ramos García Marco Antonio, Almeida Gutiérrez Eduardo, Lupercio Mora Karina

Hospital de Cardiología del Centro Médico Nacional Siglo XXI, IMSS.

Tipo de estudio: Reporte de casos clínicos con revisión de fuentes

Introducción: Los síndromes aórticos agudos constituyen una emergencia médica. El diagnóstico puede ser desafiante, ya que la presentación clínica puede ser aguda o subaguda. Existen diversas propuestas acerca de la fisiopatología que comparten los síndromes aórticos agudos; sin embargo, en la actualidad se sabe que el hematoma intramural y la disección aórtica son dos entidades diferentes. Descripción del caso: Masculino de 61 años. Ingresa por dolor torácico con choque cardiogénico. Coronariografía: arterias sin lesiones. Angiotomografía: hematoma intramural desde seno de Valsalva posterior, flap de disección desde arco proximal a ambas iliacas comunes y troncos supraaórticos. La resonancia magnética muestra infarto transmural en territorio de circunfleja y disección 
aórtica Stanford-A. Se realizó debranching y posteriormente stent coronario. Metodología: Se realizó una búsqueda con el método booleano, de términos MeSH «aortic dissection» [and] «intramural hematoma» en las bases de datos de evidencia científica arbitrada indizada (PubMed y Cochrane) y no indizadas (Google Scholar). Resultados: Un ensayo clínico prospectivo encontró que, en pacientes mayores de 60 años, el debranching híbrido del arco aórtico se asoció a menor estancia intrahospitalaria, menor incidencia de eventos neurológicos, reintervención y mayor supervivencia a mediano plazo comparado con el reemplazo total del arco aórtico. Discusión: La asociación de hematoma intramural y disección aórtica Stanford A en un mismo paciente es rara. En la actualidad, el manejo de los pacientes con disección aórtica Stanford A es quirúrgico; sin embargo, el manejo de los pacientes con hematoma intramural puede ser conservador en primera instancia.

\subsection{Tratamiento de aneurisma intracraneal mediante embolización con coils de platino. Reporte de un caso}

López López Fernando, Beltrán Nevárez Octavio,

Castro Ramírez Gildardo, Triano Doroteo JoséLuis, Ríos Corral Marco Antonio, Córdova Leyva Luis Armando, Hernández Mejía Rogelio

Centro Cardiovascular de Culiacán.

Tipo de estudio: Registros locales o nacionales

Introducción: La implantación de coils metálicos en aneurismas intracraneales mediante terapia endovascular es un método novedoso para el tratamiento definitivo de estas malformaciones vasculares. Además de ello, este método tiene beneficios en tiempo de procedimiento, costo total, tiempo de hospitalización, medio de contraste y radiación. Objetivo: Documentar la experiencia del tratamiento intervencionista de aneurisma intracraneal en centro cardiovascular privado. Metodología: Documentación directa de tratamiento intervencionista de aneurisma cerebral a un paciente femenino de 48 años con antecedente de cefalea intensa refractaria a tratamiento tradicional. Mediante panangiografía cerebral se diagnostica aneurisma sacular de cuello ancho del segmento oftálmico de la arteria carótida interna derecha. Resultados: Mediante introductor inguinal catéter guía 8 Fr hasta segmento cervical de carótida interna derecha, se retira guía hidrófila y navega microcatéter 45 grados de curvatura hasta el interior del aneurisma del segmento oftálmico de la carótida interna derecha, se retira microguía y a través de microcatéter se navega stent neurológico de nitinol de $5 \times 20 \mathrm{~mm}$ hasta el segmento oftálmico sin incidentes y se libera stent en cuello de aneurisma; se colocan coils de platino de $4 \times 8,2 \times 2,3 \times 6$ y $2 \times 2$ al interior del aneurisma y se libera stent neurológico. Discusión y conclusiones: Excelente respuesta al tratamiento, sin accidentes ni incidentes, muy buena recuperación; postoperatorio similar a intervención ambulatoria. Excelente alternativa de tratamiento intervencionista con bajo riesgo y recuperación rápida del paciente.

\subsection{Hemorragia en acceso radial en intervencionismo coronario. Eficacia y seguridad a largo plazo}

López López Fernando, Beltrán Nevárez Octavio,

Castro Ramírez Gildardo, Triano Doroteo José Luis,

Ríos Corral Marco Antonio, Córdova Leyva Luis Armando

Centro Cardiovascular de Culiacán.

Tipo de estudio: Registros locales o nacionales

Introducción: La vía radial ha demostrado sus beneficios al compararse con la vía femoral y otras vías de acceso tradicionales. Entre sus beneficios están el tiempo del procedimiento y un menor índice de complicaciones. En este artículo se aborda la incidencia de hemorragias y complicaciones vasculares. Objetivo: Evidenciar la experiencia en el uso del abordaje radial, su efectividad a largo plazo en la reducción de complicaciones vasculares y de episodios de hemorragia en nuestro centro cardiovascular. Metodología: Se seleccionó y utilizó la vía radial derecha como primera opción de

Tabla 7.13.1: Hemorragia en acceso radial en intervencionismo coronario.

- 1,700 procedimientos coronarios diagnósticos totales

- Edad promedio 63 años. $54.7 \%$ masculinos, $45.3 \%$ femeninos

- Dx's principales: SICASEST $52.88 \%$, SICACEST 29\% y cardiopatía estable $18.11 \%$

- Vía radial derecha: $93.5 \%$ femoral derecha $4 \%$ y radial izquierda $2.5 \%$

- Presentación de hematomas en vía de acceso: $0.58 \%$ del total de casos, cuatro en radial derecha, cuatro en femoral derecha y dos en radial izquierda

- Incidencia global de complicaciones: $<1 \%$

Figura 7.12.1.
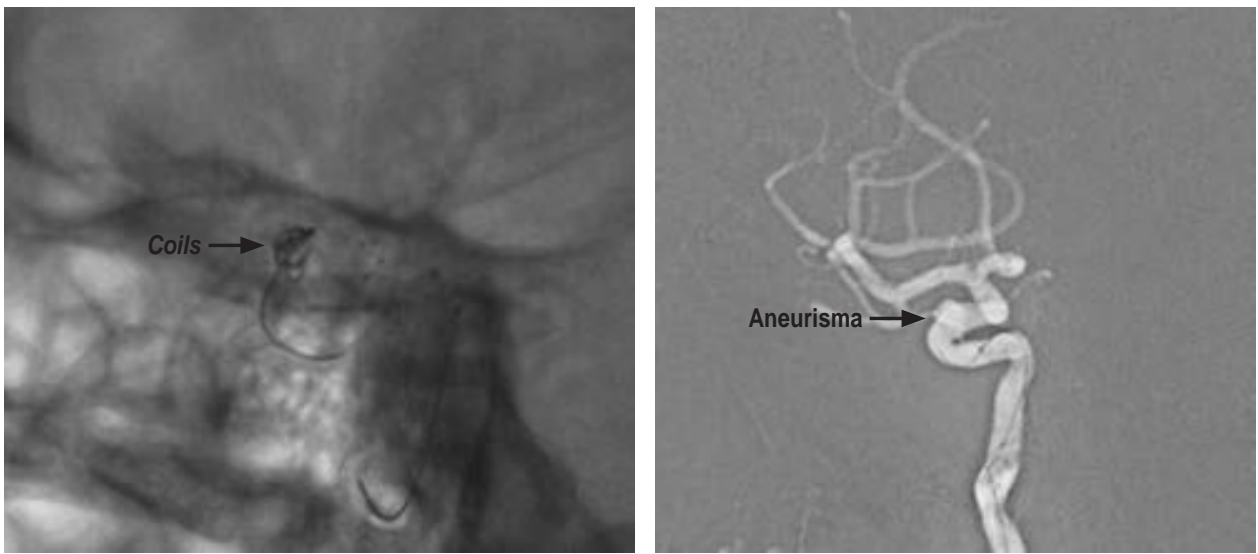
acceso vascular cuando fue posible; se analizó el éxito y fracaso de la misma y la conversión a la vía radial izquierda y femoral; tiempo de estancia en recuperación, las complicaciones en el sitio de acceso vascular y los episodios de hemorragia. Resultados: 1,700 procedimientos coronarios diagnósticos. La edad promedio fue de 63.92 años; $54.7 \%$ hombres y $45.3 \%$ mujeres. Diagnóstico principal: síndrome coronario agudo sin elevación del segmento ST en $52.88 \%$, cardiopatía estable en $18.11 \%$, síndrome coronario agudo con elevación del segmento ST en $29 \%$. Se realizaron 1,232 cateterismos diagnósticos y 468 angioplastias; 454 stents totales, la mayoría farmacoactivos en $83.7 \%$. Vías de abordaje: radial derecha $93.5 \%$, femoral derecha $4 \%$ y radial izquierda 2.5\%. Las complicaciones presentadas fueron: 10 hematomas por sangrado en el sitio de punción (0.58\%). Incidencia global de complicaciones: menos de 1\%. Discusión y conclusiones: El acceso por la vía radial demostró seguridad al reducir el riesgo de sangrado mayor en el acceso vascular, presentando una tasa de episodios de sangrado de $0.58 \%$.

\subsection{Oclusión coronaria crónica total y angioplastia coronaria transluminal percutánea}

López López Fernando, Beltrán Nevárez Octavio,

Castro Ramírez Gildardo, Triano Doroteo José Luis, Ríos Corral Marco Antonio, Córdova Leyva Luis Armando, Hernández Mejía Rogelio

Centro Cardiovascular de Culiacán.

Tipo de estudio: Registros locales o nacionales

Introducción: Una intervención coronaria percutánea exitosa en oclusión coronaria crónica total brinda beneficios como la mejoría en la función ventricular izquierda, alivio de los síntomas y gran ventaja en la supervivencia cuando se compara al mismo tipo de lesión con resultado fallido. Factores como percepción de bajo riesgo del procedimiento y poca experiencia del operador en la técnica han determinado peligrosas incidencias bajas. Objetivo: Investigar y documentar la estadística de pacientes atendidos con diagnóstico de oclusión coronaria crónica total en quienes se realizó angioplastia coronaria transluminal percutánea. Metodología: Se incluyeron de manera retrospectiva a los pacientes entre 2012 a 2017 en quienes se realizó angioplastia coronaria transluminal percutánea presentando lesiones de tipo oclusión coronaria crónica total. Se analizó la totalidad de presentación de oclusión coronaria crónica total, el éxito del procedimiento, el porcentaje y tipo de stent, el tiempo de procedimiento, medio de contraste utilizado, fluoroscopia y Kerma aéreo. Resultados: De 2012 a 2017 se realizaron 468 angioplastias coronarias y se encontró en 53 pacientes (11.32\%) hallazgos de oclusión coronaria crónica total. Se realizó angioplastia coronaria transluminal percutánea mediante técnica

Tabla 7.14.1: СТO y ACTP.

- 53 casos totales CTO

- 45 casos ACTP exitosa con uso de técnica anterógrada por escalamiento de guías (84.9\%)

- $98.6 \%$ éxito colocación de stent ( $87 \%$ farmacoactivo)

- Tiempo total procedimiento: $61.26 \pm 21.1 \mathrm{~min}$

- Medio de contraste: $161.5 \pm 45.6 \mathrm{~mL}$

- Tiempo de fluoroscopia: $15.03 \pm 2.3 \mathrm{~min}$

- Radiación mGy: 3,961.33 \pm 113 mGy anterógrada por escalamiento de guías exitosa en 45 del total de estos pacientes (84.9\%). En $98.6 \%$ de los casos se logró colocar stent para la solución de las lesiones y de ellos $87 \%$ fueron stents farmacoactivos. Tiempo de procedimiento: $61.26 \pm 12.1$ minutos. Medio de contraste: $161.50 \pm 45.6 \mathrm{~mL}$. Fluoroscopia: $15.03 \pm 2.3$ minutos, Kerma aéreo 3,961.33 \pm 113 mGy. Discusión y conclusiones: La recanalización exitosa en oclusiones coronarias crónicas totales reduce los síntomas de angina, la carga isquémica y mejora la función del ventrículo izquierdo.

\subsection{Síndrome coronario agudo con elevación del segmento ST y angioplastia coronaria}

López López Fernando, Beltrán Nevárez Octavio,

Castro Ramírez Gildardo, Triano Doroteo José Luis, Ríos Corral Marco Antonio, Córdova Leyva Luis Armando, Hernández Mejía Rogelio

Centro Cardiovascular de Culiacán.

Tipo de estudio: Registros locales o nacionales

Introducción: El síndrome coronario con elevación del segmento ST se asocia con la ruptura de una placa aterosclerótica inestable, con oclusión aguda por trombo de una o más arterias epicárdicas en un paciente sin antecedente de isquemia previa importante. El tratamiento inicial va dirigido a la apertura urgente de la arteria responsable, ya sea por trombólisis o revascularización percutánea. Objetivo: Evaluar los resultados y la experiencia de los casos de atención de síndrome coronario agudo con elevación del segmento ST mediante angioplastia coronaria con colocación de stent. Metodología: Se evaluaron los casos con diagnóstico clínico y electrocardiográfico del síndrome coronario agudo con elevación del segmento ST en quienes se realizó angioplastia coronaria con colocación de stent. Se analizó el tiempo de procedimiento en todos los casos, el tipo de stent utilizado, el éxito de revascularización y la mortalidad a 30 días. Resultados: Se realizaron 468 angioplastias coronarias; 332 pacientes con diagnóstico de síndrome coronario agudo sin elevación del segmento ST y 136 pacientes con diagnóstico de síndrome coronario agudo con elevación del segmento ST. Cien por ciento se realizó angioplastia coronaria, se clasificaron por tipo de infarto: anteroseptal 68 casos, posterior-inferior 68 casos. Tiempo de procedimiento: $49.16 \pm 27.32 \mathrm{~min}$. Se utilizaron stent farmacoactivos en $90.22 \%$ de los casos. Biolimus 58\%, everolimus $30 \%$ y no farmacoactivos en $9.77 \%$. Se logró revascularización en $100 \%$ de los pacientes. Complicaciones: dos casos de muerte postangioplastia (trombosis probable del stent) y choque cardiogénico. Discusión y conclusiones: Iniciativas como la atención 24/7 han logrado disminuir el tiempo de atención de estos pacientes al mínimo, logrando abatir en gran medida la tasa de mortalidad de origen cardiológico.

Tabla 7.15.1: SICACEST y ACTP.

- 468 casos totales ACTP

- 322 SICASEST y 136 SICACEST

- Clasificación de infartos: anteroseptal 68 casos, posteroinferior 68 casos

- Tiempo puerta-puerta: $49.16 \pm 27.32 \mathrm{~min}$

- Revascularización exitosa en $100 \%$ de los casos

- Presentación de muerte post ACTP: $1.4 \%$ del total de los casos (uno trombosis del stent y uno choque cardiogénico) 


\subsection{Síndrome de Takotsubo. Experiencia de 14 años y revisión de la literatura}

López López Fernando, Beltrán Nevárez Octavio, Castro Ramírez Gildardo, Triano Doroteo JoséLuis, Ríos Corral Marco Antonio, Córdova Leyva Luis Armando, Hernández Mejía Rogelio Centro Cardiovascular de Culiacán.

Tipo de estudio: Registros locales o nacionales

Introducción: La discinesia apical transitoria, síndrome de Takotsubo o síndrome de corazón partido es una enfermedad de reciente descripción con características de síndrome coronario agudo, por lo general presenta un supradesnivel del segmento ST y elevación de biomarcadores sin hallazgos de lesiones coronarias. Como característica principal, de manera transitoria, adopta el ventrículo izquierdo la forma de una vasija japonesa usada para atrapar pulpos. Objetivo: Investigar, documentar e informar la prevalencia de pacientes atendidos en nuestro centro cardiovascular con diagnóstico de síndrome de Takotsubo. Metodología: Este es un estudio retrospectivo en el cual se incluyeron a todos los pacientes del periodo de 2012 a 2018 con diagnóstico de síndrome coronario agudo que además fueron sometidos a coronariografía diagnóstica y presentaron características en ventriculograma de síndrome de Takotsubo así como los criterios diagnósticos del mismo. Resultados: Se realizaron 1,042 coronariografías con diagnóstico de síndrome coronario agudo con elevación del segmento ST. Dieciséis casos totales (1.53\%), 15 mujeres y un hombre. Edad promedio de 59 años. Todas las ventriculografías mostraron hipocinesia severa anteroapical y fracción de eyección del ventrículo izquierdo de $49.5 \%$. Como factor de riesgo cardiovascular presentaron hipertensión arterial en $100 \%$ de los casos y aterosclerosis leve en seis pacientes. En todos los casos no existieron lesiones significativas. Todos los pacientes presentaron síntomas de estrés de tipo emocional, personal y laboral. Cien por ciento tuvieron reversibilidad de las alteraciones ventriculares. Discusión y conclusiones: Aunque es más frecuente en mujeres, su prevalencia total es baja y su origen aún es desconocido, se siguen como hipótesis de la enfermedad el lupus eritematoso, espasmo vascular, etcétera.

\subsection{Trombosis del stent. Resultado comparativo a largo plazo del uso de ticagrelor versus clopidogrel}

López López Fernando, Beltrán Nevárez Octavio,

Castro Ramírez Gildardo, Triano Doroteo JoséLuis, Ríos Corral Marco Antonio, Córdova Leyva Luis Armando, Hernández Mejía Rogelio

Centro Cardiovascular de Culiacán.

Tipo de estudio: Registros locales o nacionales
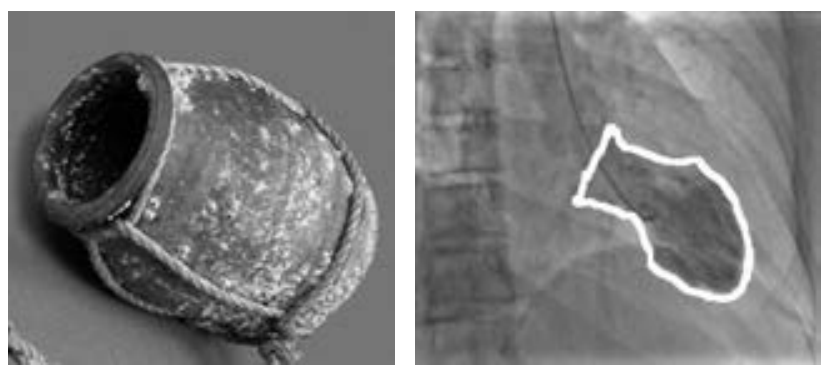

Figura 7.16.1.
Tabla 7.17.1: Trombosis del stent ticagrelor vs clopidogrel.

- 1,700 procedimientos coronarios diagnósticos

- 468 angioplastias coronarias $(27.5 \%)$

- Colocación 454 stent totales

- Dx ACTP: SICASEST 71\%, SICACEST $29 \%$

- DAPT: ticagrelor $75.6 \%$, clopidogrel $24.3 \%$

- Stent trombosis: tres casos en grupo ticagrelor y ocho casos en grupo clopidogrel

- Hemorragias: seis casos en grupo ticagrelor y tres casos en grupo clopidogrel

- $100 \%$ presentación de casos (9) de hemorragia en acceso de arteria radial derecha

Introducción: La terapia antiplaquetaria dual ha mostrado la reducción de la trombosis del stent postangioplastia en los síndromes coronarios. Ticagrelor, como nuevo antiagregante plaquetario con indicación clase IB en las guías americanas y europeas de cardiología, al ser comparado contra el clopidogrel, su competidor directo, ha demostrado tener ventajas competitivas específicas como inicio de acción más rápido y reversibilidad. Objetivo: Demostrar la superioridad de ticagrelor sobre clopidogrel en eficacia y seguridad para la prevención de stent trombosis sin incrementar el sangrado en pacientes con síndrome coronario agudo. Metodología: Se incluyeron de manera retrospectiva a todos los pacientes con diagnóstico de síndrome coronario agudo con y sin elevación del segmento ST demostrada por electrocardiografía que fueron sometidos a angioplastia coronaria con implante de stent farmacoactivos y no farmacoactivos. Resultados: 1,700 procedimientos diagnósticos; 468 angioplastias, colocación de 454 stents totales, 83.7\% fueron farmacoactivos y $16.29 \%$ no farmacoactivos. Biolimus $34.21 \%$, everolimus $36.84 \%$, paclitaxel $12.63 \%$, zotarolimus $16.31 \%$. Diagnóstico en angioplastia: síndrome coronario agudo sin elevación del ST en $71 \%$ y síndrome coronario agudo con elevación del ST en 29\%. Edad promedio: 63.92 años. Se utilizó ticagrelor en $75.6 \%$ y clopidogrel en $24.3 \%$. Stent trombosis definitiva ocurrió en tres casos en el grupo con ticagrelor y en ocho casos en el grupo con clopidogrel. Hemorragias por punción: seis en el grupo ticagrelor y tres en clopidogrel. Discusión y conclusiones: En comparación con las diferentes opciones de tratamiento antiplaquetario, estos datos evidenciaron mayor seguridad para la presentación de trombosis del stent con el uso de ticagrelor.

\subsection{En épocas de COVID-19. Infarto agudo de miocardio con intervención coronaria percutánea de rescate}

González Olvera Jimena Alejandra, Romero Sánchez Javier,

Almeida Gutiérrez Eduardo, Lupercio Mora Karina

Hospital de Cardiología del Centro Médico Nacional Siglo XXI.

Tipo de estudio: Reporte de casos clínicos con revisión de fuentes

Introducción: Las complicaciones cardiovasculares son muy frecuentes en pacientes con enfermedad por coronavirus 2019 (COVID-19). El infarto agudo de miocardio con elevación del segmento ST (IAMCEST) representa la principal manifestación clínica en ellos, en $40 \%$ no se encuentra la lesión responsable en coronariografía. El manejo representa un reto en pacientes infectados por el síndrome respiratorio agudo por coronavirus 2 (SARS-CoV-2). Descripción del caso: Masculino de 57 años, sin factores de riesgo ni historia 

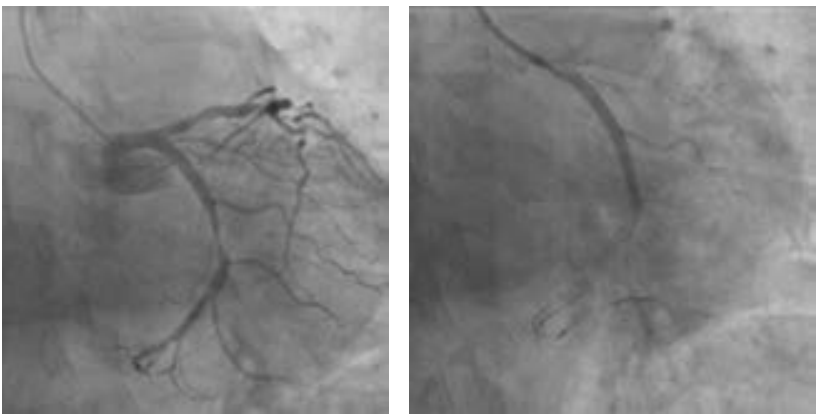

Figura 7.18.1: Intervencionismo coronario percutáneo a arteria circunfleja.

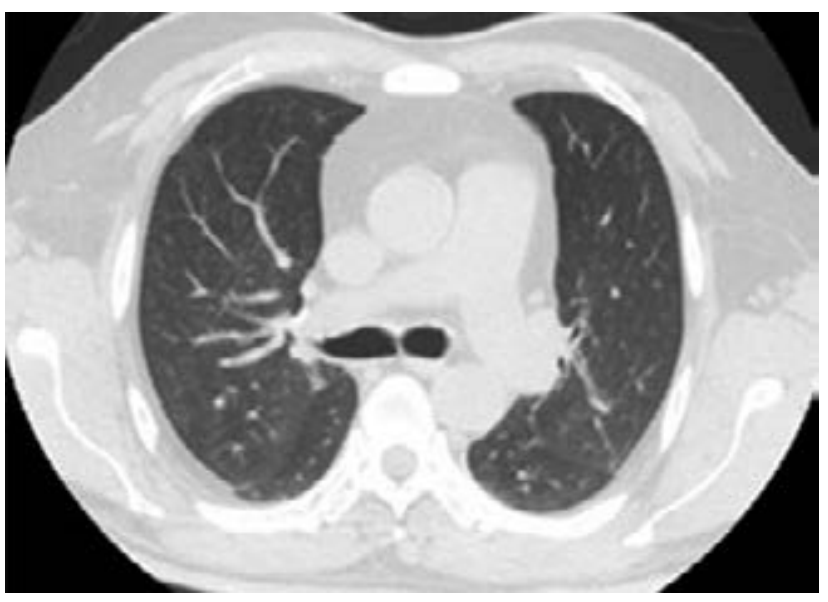

Figura 7.18.2: Corte axial de tomografía de tórax simple con reporte: parénquima pulmonar zona de vidrio deslustrado de predominio subpleural afectación menor de 5\% (un punto); zona de consolidación y escaso derrame pleural, en el lado izquierdo zona de vidrio deslustrado de localización subpleural con afectación menor de 5\% (un punto) clasificación CO-RADS: CO-RADS 3: incierto. Índice de severidad: afección leve (dos puntos).

cardiovascular, triaje respiratorio negado. Ingresa con diagnóstico de IAMCEST. Se realiza trombólisis fallida con tenecteplasa $40 \mathrm{mg}$, ingresa a intervencionismo coronario percutáneo (ICP) de arteria circunfleja colocando dos stents (Figura 7.18.1). Toma de reacción en cadena de polimerasa (PCR) de SARS-CoV-2 positivo a las 72 horas. Metodología: A través del método booleano se realizó búsqueda de términos IAMCEST en pacientes con COVID-19, tratamiento, manejo y diagnóstico en las bases de datos con repositorios de evidencia científica arbitrada indizada (PubMed) y no indizadas (Google Scholar). Resultados: Se ha observado aumento de IAMCEST e IAMCEST «like», en pacientes con COVID-19, por la capacidad del virus de causar daño miocárdico, miopericarditis y tormenta de citocinas; los algoritmos actuales de diagnóstico resaltan la importancia de descartar causas secundarias de elevación del segmento ST. Se acepta ICP como el estándar de oro para pacientes con IAMCEST más COVID-19 confirmado o probable. Discusión: Se realiza algoritmo diagnóstico de acuerdo con guías actuales para diagnóstico de IAMCEST en paciente con COVID-19, así como tratamiento estándar de oro con ICP y tratamiento de arteria responsable, sin complicaciones. Paciente sin riesgo cardiovascular con sospecha de IAMCEST secundario a COVID-19.

\subsection{Origen anómalo del tronco coronario izquierdo y enfermedad aterosclerótica, un reto terapéutico}

Martínez Maltos Roberto,* García Jiménez Yoloxóchitl, ${ }^{\ddagger}$

Márquez López Jesús Sinue, ${ }^{\ddagger}$ Moreno Castillo Gustavo, ${ }^{\ddagger}$

Pérez Roa Herlich Francisco, ${ }^{\ddagger}$ Sanabria Rosales Carlos Arturo ${ }^{\ddagger}$

* Instituto Mexicano del Seguro Social. ${ }^{\ddagger}$ UMAE

Hospital de Especialidades No. 14, Veracruz.

Tipo de estudio: Reporte de casos clínicos con revisión de fuentes

Introducción: El origen anómalo de las arterias coronarias tiene una prevalencia de $0.44 \%$. El origen anómalo del TCl del seno coronario derecho es de los nacimientos anómalos menos prevalentes. Esta patología se asocia con muerte súbita cardiaca, un riesgo de mortalidad de $6.3 \%$ a 20 años. Descripción del caso: Masculino de 58 años, hipertenso, dislipidémico, tabaquismo. Estudiado por angina al esfuerzo. El ecoestrés con cicloergómetro mostró isquemia en región anteroseptal e inferoseptal. El cateterismo documentó origen del TCl en seno de Valsalva derecho, sin efecto de milking en el TCl, placa en arteria circunfleja. En la actualidad, en clase I con tratamiento antiisquémico. Sesión médica quirúrgica diferida por la conversión hospitalaria. Metodología: Se realiza una revisión sistemática y exhaustiva de las revistas indexadas al 2020 disponibles en la base de datos de PubMed, Medline, Science Direct, identificando las palabras claves: anomalous origin left coronary artery, dando relevancia al factor de impacto. Resultados: La dificultad en el tratamiento percutáneo de estas lesiones depende del diámetro de la raíz aórtica, el nivel de soporte, el ángulo de despegue, ubicación de la lesión y material para la revascularización. Este caso se decidió someter a sesión médica ante las características de la lesión y la documentación de isquemia en un territorio diferente a ésta. Discusión: No existe evidencia sólida en cuanto al manejo y seguimiento de estos pacientes. La literatura sugiere la restricción

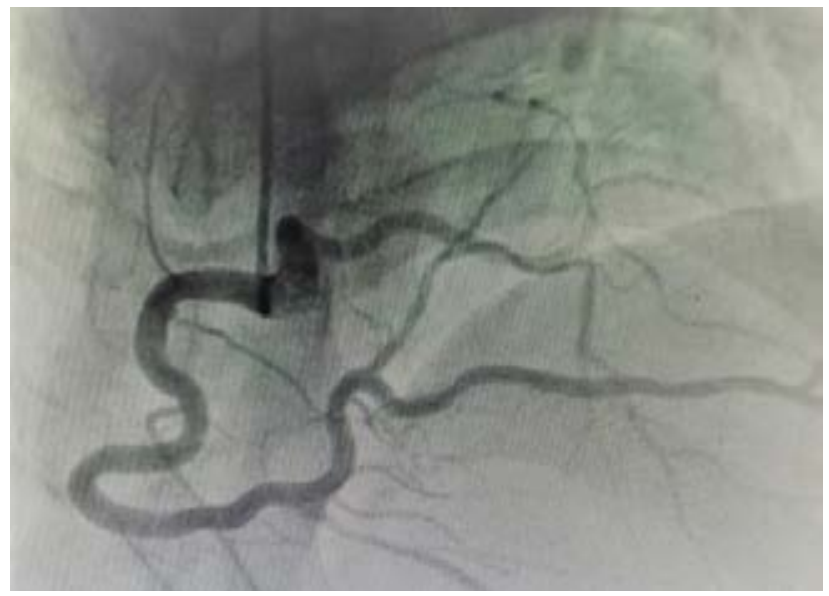

Figura 7.19.1: Angiografía coronaria en la cual se observa nacimiento anómalo del tronco coronario izquierdo con origen del seno coronario derecho. 


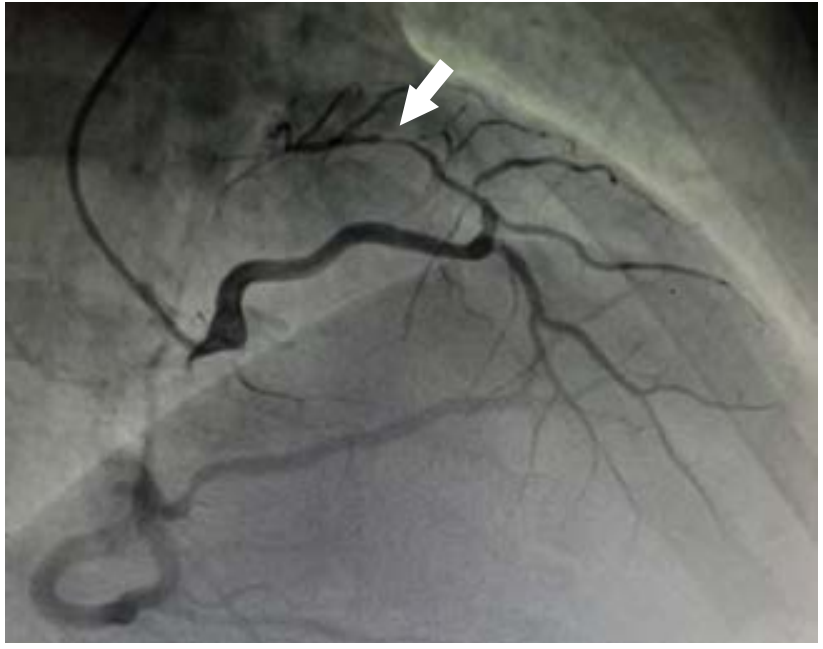

Figura 7.19.2: Angiografía coronaria en la cual se observa nacimiento anómalo del tronco coronario izquierdo y placa distal de la arteria circunfleja (flecha).

de deportes competitivos y la corrección percutánea o quirúrgica cuando existan características anatómicas de alto riesgo, síntomas refractarios, arritmias y estudios de isquemia positivos. Existen buenos resultados con el uso de betabloqueadores, aunque no hay evidencia al comparar el manejo conservador y el quirúrgico.

\subsection{Nacimiento anómalo de arteria descendente anterior e infarto sin elevación del segmento ST}

Loaiza Sánchez Juan Felipe, Campos Vidal Fernando,

González Zazueta Rafael, Almeida Gutiérrez Eduardo,

Lupercio Mora Karina

Hospital de Cardiología del Centro Médico Nacional Siglo XXI.

Tipo de estudio: Reporte de casos clínicos con revisión de fuentes

Introducción: Las anomalías de arterias coronarias ocurren hasta en $1 \%$ de coronariografías por sospecha de enfermedad obstructiva y 0.3\% de necropsias; siendo el infarto con elevación del segmento ST o sus equivalentes una rara presentación. El origen anómalo de la arteria descendente anterior generando una doble descendente anterior fue descrita y clasificada por Spindola-Franco en 1983. Descripción del caso: Masculino de 61 años, hipertensión arterial, tabaquismo, sedentario; historia de infarto anterior hace 17 años. Ingresa con angina. Electrocardiograma: lesión subendocárdica V3-V6, DI-aVL y elevación del ST aVR. Cateterismo: enfermedad coronaria en múltiples vasos, origen anómalo de descendente anterior (DA) del segmento proximal coronaria derecha (CD), stent de la DA con reestenosis 95\%, CD suboclusiva, se realiza angioplastia exitosa de ambas arterias. Metodología: Se realizó una búsqueda en bases de datos de revistas indexadas con factor de impacto PubMed y en otras bases de datos de publicaciones como Google Scholar, se eligieron artículos de revisión, guías de práctica clínica y series de casos relacionadas al nuestro. Resultados: Las anomalías coronarias causan dolor torácico, muerte súbita, arritmias e infarto, esta última de rara presentación; la identificación del vaso culpable y su tratamiento puede ser difícil en el contexto agudo; los hallazgos angiográficos corresponden a un

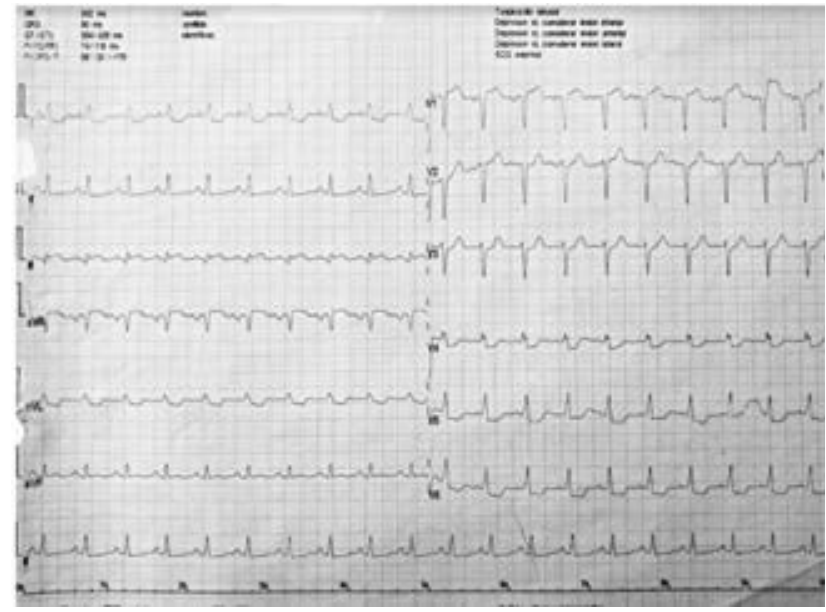

Figura 7.20.1: ECG 12 derivaciones, FC 115 Ipm, eje 60 grados, P 80 ms, p +/-, PR 160 ms, QRS 80 ms, transición en V4, QT 320 ms, QTC 443 ms, desnivel negativo del segmento ST en V3 $0.1 \mathrm{mV}$, V4 $0.2 \mathrm{mV}$, V5 $0.2 \mathrm{mV}$, V6 $0.2 \mathrm{mV}$, DI $0.2 \mathrm{mV}$, aVL $0.1 \mathrm{mV}$, desnivel positivo del segmento $S T$ aVR $0.1 \mathrm{mV}$.
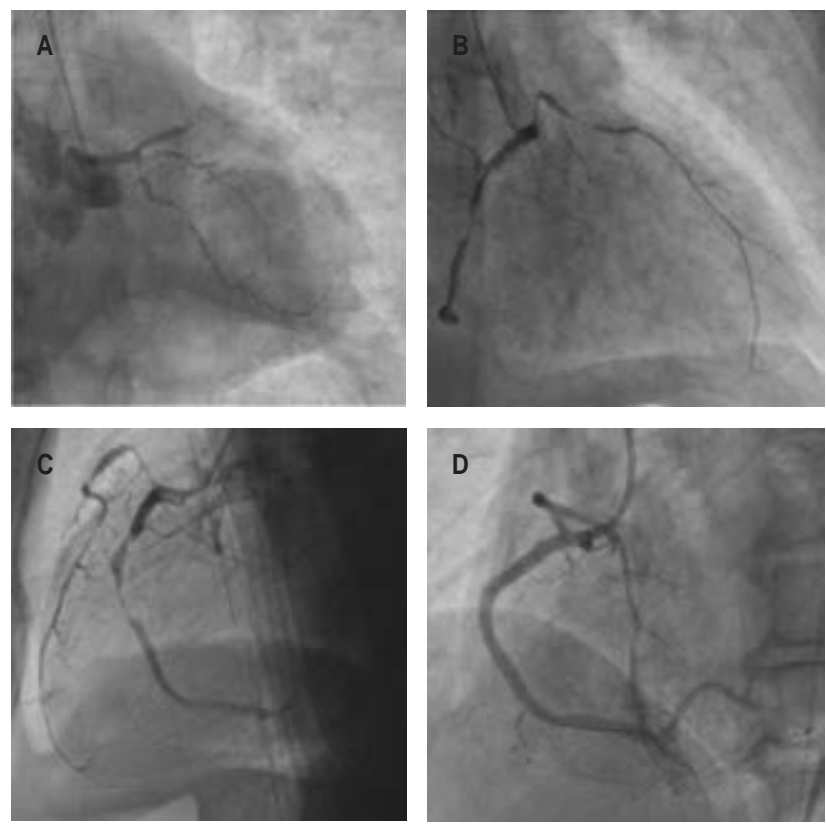

Figura 7.20.2: Angiografía coronaria, A) Proyección oblicua anterior izquierdo con caudo, se observa tronco coronario trifurcado con descendente anterior con oclusión total proximal, termina en punta de lápiz, ramus intermedio lesión 75\% proximal, difusamente enferma, circunfleja no dominante lesión proximal 95\% y distal 90\%. B) Oblicua anterior derecha con coronaria derecha lesión proximal 60\%, medio 99\%, descendente anterior de origen en coronaria derecha proximal con lesión 95\%. C) Lateral, con coronaria derecha dominante lesión proximal 60\% y medio 99\%, descendente anterior lesión proximal 95\% y medio 95\%. D) Oblicua anterior izquierda postangioplastia. 
doble descendente anterior tipo 4, clasificación Spindola-Franco: una descendente anterior corta originada en tronco coronario izquierdo y una descendente anterior de coronaria derecha. Discusión: El origen anómalo de esta arteria podría relacionarse a enfermedad aterosclerótica sumado a factores de riesgo cardiovascular que predisponen a síndrome coronario agudo; en la correlación electrocardiográfica y la angiografía coronaria se consideró responsable a la arteria descendente anterior. Realizar intervencionismo coronario percutáneo es un reto por la elevada complejidad anatómica y técnica.

\subsection{Infarto agudo de miocardio con elevación del segmento ST sin evidencia de obstrucción coronaria}

López López Fernando, Beltrán Nevárez Octavio,

Castro Ramírez Gildardo, Triano Doroteo José Luis, Ríos Corral Marco Antonio, Córdova Leyva Luis Armando, Hernández Mejía Rogelio

Centro Cardiovascular de Culiacán.

Tipo de estudio: Registros locales o nacionales

Introducción: Con mayor frecuencia se detectan pacientes con signos y síntomas de cardiopatía isquémica sin evidencia de obstrucción coronaria (estenosis $\leq 50 \%$ ). Aunque estadísticamente $10 \%$ de los pacientes que poseen síndrome coronario no tienen evidencia de enfermedad coronaria, aún no queda claro el porcentaje que presentan infarto al miocardio con elevación del ST sin evidencia de obstrucción coronaria. Objetivo: Revisar y documentar la incidencia de infarto agudo de miocardio con elevación del segmento ST sin obstrucción vascular coronaria mediante coronariografía diagnóstica. Metodología: Se incluyeron a todos los pacientes de 2012 a 2019 con diagnóstico de infarto agudo de miocardio con elevación del segmento ST sin obstrucción coronaria angiográfica. Se clasificaron como diagnósticas aquellas coronariografías en las que hubo ausencia de enfermedad coronaria obstructiva (estenosis menor o igual al 50\%). Se excluyeron pacientes con diagnóstico de choque cardiogénico, hemorragias, embolismo pulmonar o inestabilidad hemodinámica. Resultados: Fueron 2,270 casos totales; 1,517 cateterismos y 753 angioplastias. El estudio constó de 1,354 hombres y 916 mujeres. Edad promedio 63.1 años. Cuatrocientos treinta y uno (19\%) se clasificaron como cardiopatía isquémica no obstructiva y 118 (5.19\%) presentaron estenosis < $30 \%$. Cien por ciento presentó como factor de riesgo cardiovascular hipertensión arterial; diabetes mellitus $40.36 \%$, dislipidemia $38.38 \%$, tabaquismo $66.7 \%$. En $29 \%$ se encontró arterias coronarias en tirabuzón. Vasoespasmo estuvo presente en 14 pacientes (3.24\%). Síndrome de Takotsubo se presentó en siete casos, pero no fueron considerados para el presente artículo por tener una definición distinta al infarto de miocardio. Discusión y conclusiones: El pronóstico a largo plazo de esta entidad involucra al reconocimiento temprano de la etiología y los factores de riesgo involucrados tales como hipertensión arterial, diabetes mellitus, dislipidemia y tabaquismo.

\subsection{Experiencia a largo plazo en el tratamiento intervencionista de tromboembolia pulmonar aguda}

López López Fernando, Beltrán Nevárez Octavio,

Castro Ramírez Gildardo, Triano Doroteo José Luis, Ríos Corral Marco Antonio, Córdova Leyva Luis Armando, Hernández Mejía Rogelio

Centro Cardiovascular de Culiacán.

Tipo de estudio: Registros locales o nacionales

Introducción: Una tercera parte de los pacientes que presentan tromboembolia venosa se manifiestan como tromboembolia pul-
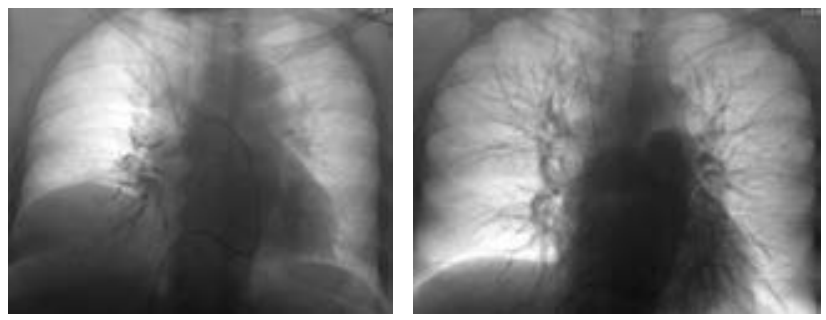

Figura 7.23.1.

monar (TEP). El riesgo de mortalidad es el doble al comparar la TEP y la trombosis venosa profunda (TVP); es de mayor incidencia en invierno y entre caucásicos y afroamericanos que en latinos y asiáticos. Otros factores de riesgo incluyen la edad avanzada, cáncer, enfermedades subyacentes cardiovasculares. Objetivo: Documentar la experiencia en el tratamiento intervencionista de pacientes con diagnóstico de TEP atendidos en nuestro centro cardiovascular. Metodología: Estudio retrospectivo y observacional. Se incluyeron a todos los pacientes del periodo de 2012 a 2019 de nuestro centro cardiovascular con diagnóstico de TEP, se registraron los cambios en la presión media de la arteria pulmonar posterior al uso de dispositivo de trombólisis ultrasónica así como los cambios angiográficos de reperfusión del parénquima pulmonar. Resultados: Siete casos de TEP, cinco hombres y dos mujeres, edad promedio 63 años, todos tratados mediante tromboaspiración. Se realizó fragmentación con catéter pigtail $6 \mathrm{Fr}$ y tromboaspiración con catéter 8 Fr. En todos los casos se dejó colocado el dispositivo de trombólisis ultrasónica durante 18-27 horas con infusión de alteplasa $1 \mathrm{mg} / \mathrm{h}$. Se realizaron angiografías de control con resultado de una disminución promedio de $21 \mathrm{mmHg}$ de presión arterial pulmonar. En $86 \%$ de los casos hubo mejoría significativa en los defectos de llenado y prácticamente ausencia de trombo residual. Discusión y conclusiones: En la actualidad, las guías del manejo indican que es recomendable estratificar el riesgo usando el índice de severidad de la embolia pulmonar y una evaluación posterior de riesgo con imágenes y biomarcadores.

\subsection{Arteria descendente anterior dual (tipo 1). Una rara anomalía coronaria}

Pacheco López Alejandro, Lupercio Mora Karina, Almeida Gutiérrez Eduardo, Ramírez Sánchez Patricia, Macossay Santiago Sigifredo, Sánchez Torres Miguel Ángel Hospital de Cardiología del Centro Médico Nacional Siglo XXI. Tipo de estudio: Reporte de casos clínicos con revisión de fuentes

Introducción: Las anomalías congénitas de las arterias coronarias son extremadamente raras con una incidencia reportada de $0.65-1.3 \%$ de angiografías coronarias. Estas anomalías incluyen el origen, trayecto y distribución de las arterias epicárdicas; dichas alteraciones son más frecuentes en la coronaria derecha; sin embargo, la descendente anterior (DA) dual sólo se ha encontrado en $0.13 \%$ de corazones normales. Descripción del caso: Masculino de 58 años. Antecedentes: diabetes mellitus 2, hipertensión arterial sistémica, dislipidemia, enfermedad renal crónica. Ingresa 12 horas previas con angina; el electrocardiograma muestra: bloqueo incompleto de rama derecha del haz de His, zona inactivable en cara inferior y pobre progresión de primer vector. Ecocardiograma: FEVI 59\%, acinesia inferolateral, 

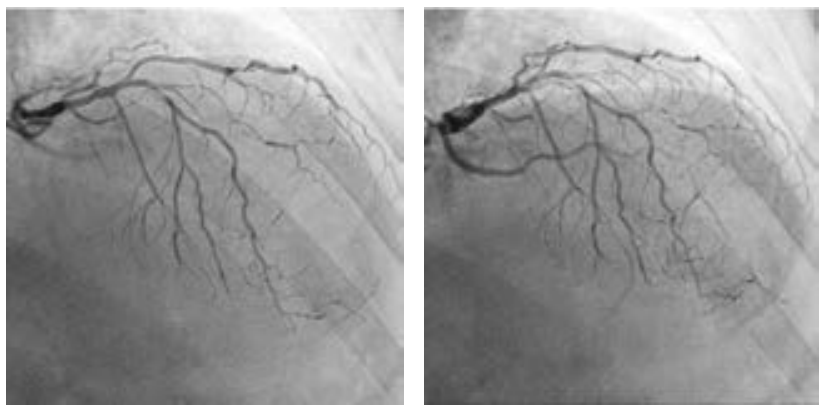

Figura 7.23.1: Angiografía que evidencia descendente anterior con doble sistema tipo 1 de Spindola-Franco.
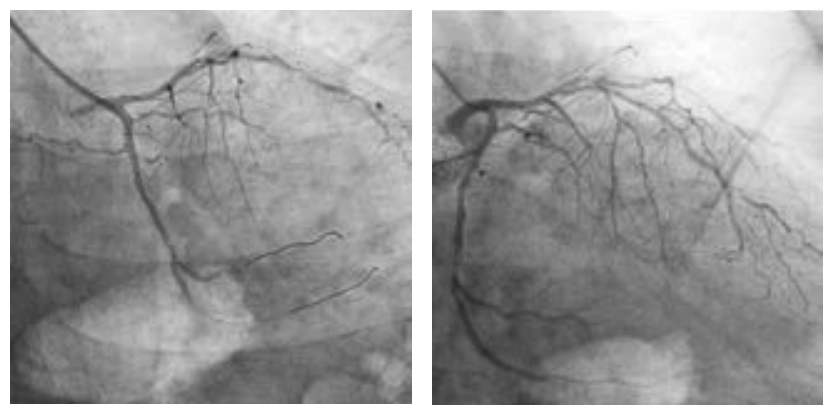

Figura 7.23.2: Angiografía proyección oblicua anterior derecha, se realiza intervencionismo coronario percutáneo a arteria circunfleja.

anteroseptal y anterior. Coronariografía: descendente anterior con doble sistema tipo 1 de Spindola-Franco. Metodología: A través del método booleano se realizó búsqueda de términos $\mathrm{MeSH}$ «dual left anterior descending coronary artery» [and] «congenital coronary anomalies» en las bases de datos con repositorios de evidencia científica arbitrada indizada (PubMed) y no indizadas (Google Scholar). Resultados: Spindola-Franco I: DA-corta por surco interventricular anterior (SIVA), DA-larga por lado ventricular anterior regresando al SIVA hasta el ápex. II: DA-corta como tipo I, DA-larga por lado ventricular derecho del SIVA. III: DA-corta como tipo I, DA-larga intramiocárdica por septum regresando al epicardio por SIVA hasta el ápex. IV: DA original y corta forman vaso corto. Discusión: De acuerdo con Spindola-Franco (1983), el paciente presenta el tipo I, que es el más frecuente (86\%). Dicha clasificación ha sido modificada por varios autores. No está claro si existe relación entre estas anomalías y ateroesclerosis; sin embargo, en arterias con múltiples bifurcaciones y flujo turbulento hay mayor tendencia a ateroesclerosis como se observa en la angiografía del paciente.

\subsection{Doble problema: disección coronaria espontánea y embolismo pulmonar. Reporte de un caso}

Pacheco López Alejandro, Lupercio Mora Karina,

Almeida Gutiérrez Eduardo, Mercado Rojas Gerardo,

Macossay Santiago Sigifredo, Esparza Pérez Denhi,

Ramírez Arias Erick

Hospital de Cardiología del Centro Médico Nacional Siglo XXI.

Tipo de estudio: Reporte de casos clínicos con revisión de fuentes
Introducción: La disección coronaria espontánea ha sido reconocida como causa rara de síndrome coronario agudo y muerte súbita cardiaca. La incidencia se ha reportado en $0.1-0.28 \%$ en series de angiografías realizadas. Se observa en jóvenes, fase periparto e idiopática, sin factores de riesgo obvios, fisiopatológicamente es diferente a la etiología ateroesclerótica. Descripción del caso: Masculino de 43 años. Dos semanas con disnea progresiva; ingresa con taquicardia, dolor torácico y disnea. Al examen físico con precordio hiperdinámico. Dímero D: 4,000 ng/mL, troponina-T-HS: normal. La angiotomografía muestra tromboembolia pulmonar subsegmentaria. Ecocardiograma: función ventricular derecha normal, con alteraciones segmentarias de la movilidad. Gammagrama cardiaco: isquemia anterior, inferior; coronariografía muestra disección coronaria tipo D coronaria derecha y descendente anterior; perfil inmunológico normal. Metodología: A través del método booleano se realizó bús-

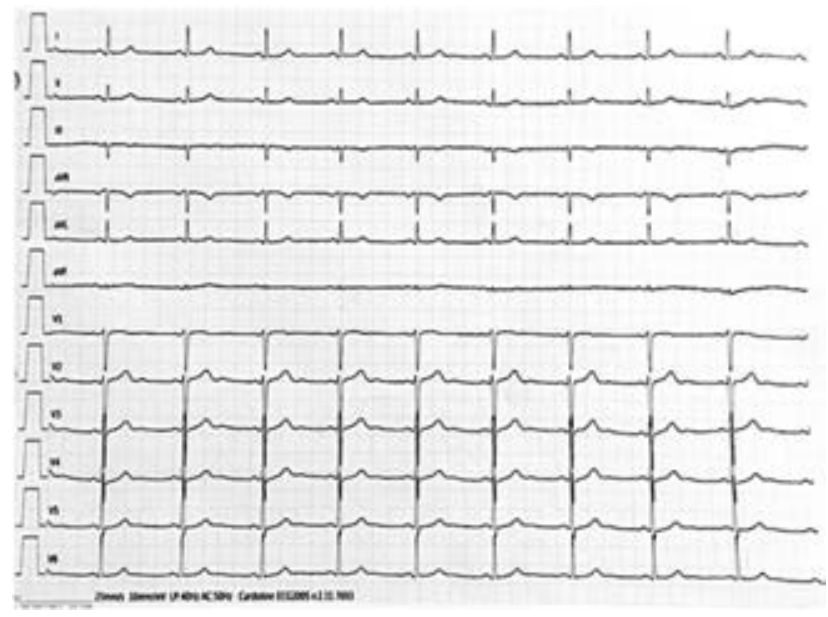

Figura 7.24.1: Electrocardiograma de 12 derivaciones calibración estándar.

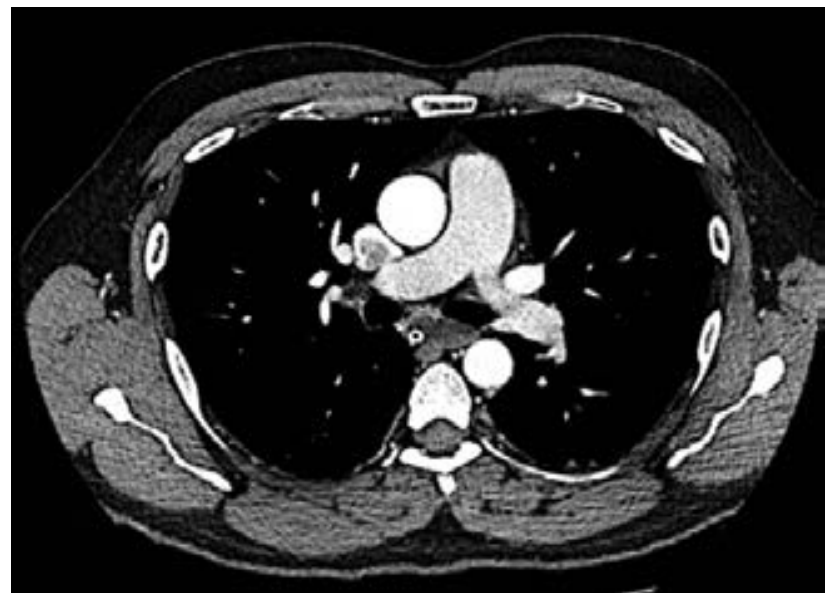

Figura 7.24.2: Angiotomografía pulmonar con defecto de llenado en ramos segmentarios y subsegmentarios de arterias pulmonares en lóbulo inferior izquierdo, centrales. 

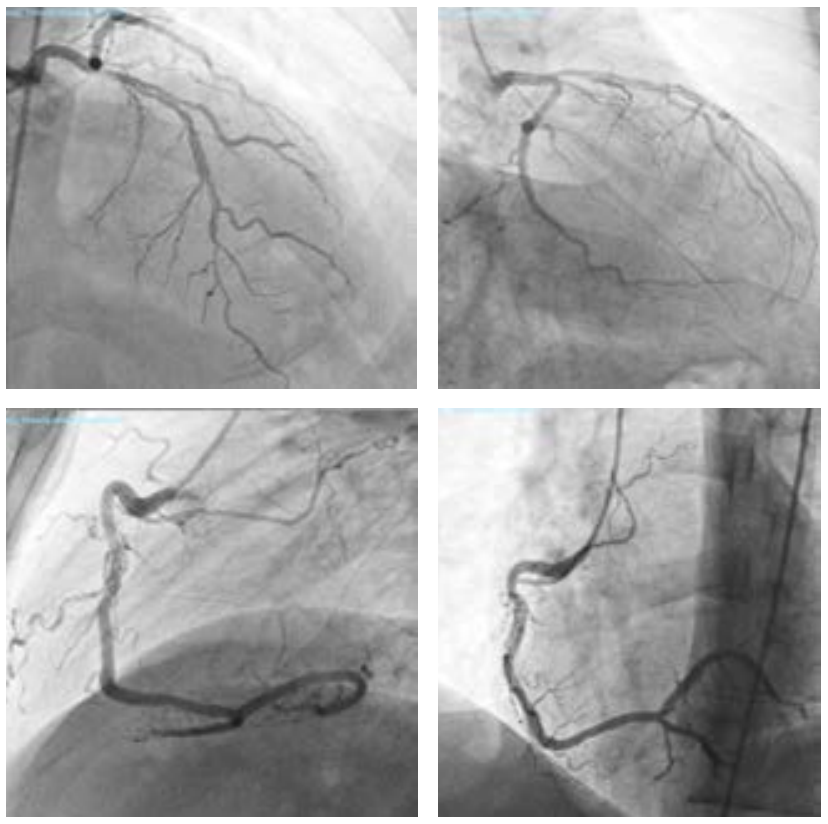

Figura 7.24.3: Angiografía coronaria en la cual se evidencia disección coronaria tipo $D$ en arteria coronaria derecha y descendente anterior.

queda de términos MeSH «spontaneous coronary artery dissection» [and] «coronary dissection» en las bases de datos con repositorios de evidencia científica arbitrada indexadas (PubMed, EBSCO, Ovid, ClinicalKey) y no indexadas (Google Scholar). Resultados: La disección coronaria espontánea es causa rara de síndrome coronario agudo; se ha descrito en pacientes con ateroesclerosis, displasia fibromuscular, ectasia, miocardiopatía hipertrófica, uso de cocaína, síndrome de Marfan y Ehlers-Danlos, se reporta también en enfermedades autoinmunes como arteritis reumática, tiroiditis autoinmune, hepatitis- $\mathrm{C}$, lupus eritematoso sistémico, sarcoidosis y enfermedad de Kawasaki. Discusión: Se han informado modalidades de tratamiento (cirugía de revascularización coronaria, angioplastia con balón, colocación de stent) con éxito variable. La terapia médica sola en pacientes sin síntomas isquémicos residuales tiene buenos resultados a largo plazo. Los pacientes que sobreviven al evento inicial tienen buen pronóstico con supervivencia de $80 \%$ a los 30 meses, independientemente de la modalidad del tratamiento.

\subsection{Closure of persistent truncus arteriosus type $a$ in adult and pulmonary arterial with dispositive VSD}

Arreguín Porras Juan Francisco, San Luis Miranda Raúl

Hospital General «Dr. Gaudencio González Garza»

del Centro Médico Nacional La Raza, IMSS.

Tipo de estudio: Estudio terapéutico

Introduction: The treatment of patients with persistent truncus arteriosus (PTA) in adult is a challenge that is because decreased compliance and the calcification on the congenital defect. These patients frequently present wide defects and pulmonary arterial hypertension, which may be related to the migration of single-disc closure devices. Therefore, it has been proposed to use doubledisc devices. Objective: To determine the safety of the strategy of closure of PTA in Adults with dispositive ocluder VSD. Methodology: From October 2016 to May 2018, in a prolective form, we studied 3 adults patients in whom realized closure of PTA with dispositive VSD ocluder. Results: The average age of the patients was 34.6 years, $100 \%$ were female with PTA type A, with class functional II; the average of systolic pressure of pulmonary artery (SPPA) was $58.3 \mathrm{~mm}$ and the average follow-up time was 8.6 months. The patients have remained stable (Table 7.25.1). Discussion and conclusions: In adult patients with persistent truncus arteriosus type A with pulmonary hypertension and limitation of functional class, its recommended realize closure of defect with double disc closure devices.

\subsection{Infarto agudo de miocardio con elevación del segmento ST en adultos mayores}

Pimentel Morales Gela, Malváez López Héctor Miguel,

Estrada Gallegos Joel, Arizmendi Uribe Efraín, Mayorquín Carranza Javier, Saturno Chiu Guillermo

Centro Médico Nacional Siglo XXI, IMSS.

Tipo de estudio: Registros locales o nacionales
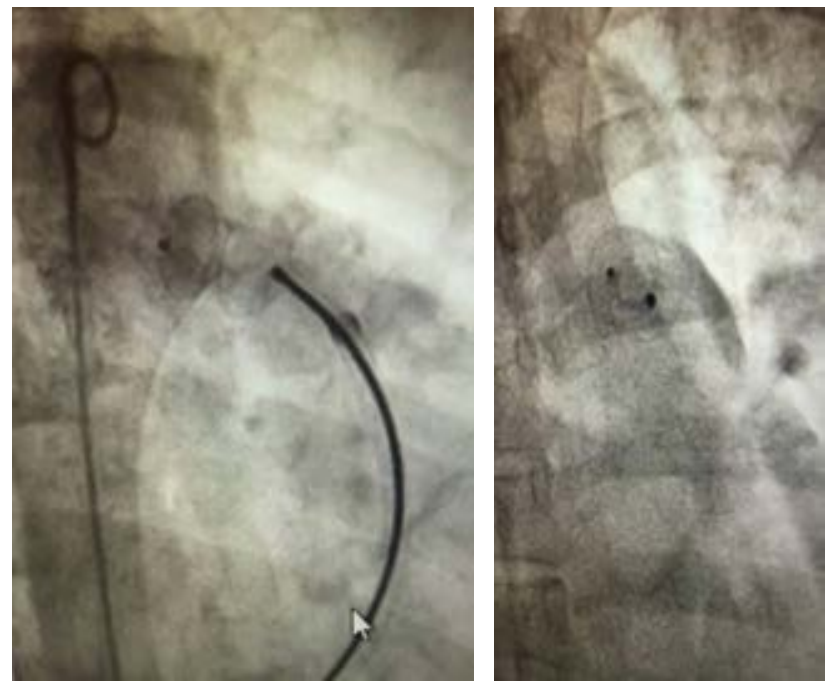

Figure 7.25.1.

Table 7.25.1.

$\begin{array}{llll}\text { Patient } & \text { PRY } & \text { RBML } & \text { MRM } \\ \text { Age } & 28 & 29 & 47 \\ \text { Sex } & \text { Female } & \text { Female } & \text { Female } \\ \text { Functional class NYHA } & \text { II } & \text { II } & \text { III } \\ \text { Morphological type } & \text { A } & \text { A } & \text { A } \\ \text { Diameter of defect (mm) } & 10 & 15 & 12 \\ \text { SPPA (mmHg) } & 68 & 57 & 50 \\ \text { Prothesis } & \text { VSDO16 } & \text { VSDO18 } & \text { VSDO16 } \\ \text { Result immediatly } & \text { Small shunt } & \text { Closure } & \text { Closure } \\ \text { Complications } & \text { No } & \text { No } & \text { No } \\ \text { Time of follow up (months) } & 8 & 12 & 6\end{array}$


Introducción: La angioplastia coronaria percutánea, los nuevos dispositivos y accesos vasculares utilizados, así como la terapia médica temprana han mostrado una mejoría en los desenlaces e incluso una reducción en la mortalidad en los pacientes que se presentan con IAMCEST; sin embargo, existe poca evidencia sobre el impacto de estas estrategias en los adultos mayores. Objetivo: Evaluar las indicaciones, resultados y desenlaces de los pacientes mayores de 65 años en el contexto de IAMCEST, sometidos a ICP primaria, mediante acceso transradial. Metodología: Se evaluaron un total de 243 pacientes mayores de 65 años que se presentaron con IAMCEST y que fueron sometidos a ICP primaria. Resultados: Edad: $72.9 \pm 6.3$ (65-93 años), hombres 70.3\%, DM2 48.1\%, HAS $66.2 \%$, hipercolesterolemia $40.7 \%$, tabaquismo $58.8 \%$, infartos previos 9.5\%, revascularización previa: ICP 6.1\%, CRVC 2.6\%, enfermedad multivaso $39.5 \%$, número de stents colocados: 1.23 \pm 0.6 , uso de tromboaspiración $43.7 \%$, FEVI $42.5 \pm 1.3 \%$, uso de GP IIb/IIla $21.8 \%$, flujo final TIMI 3 en $79.8 \%$. Seguimiento promedio de $31 \pm 8.9$ meses, 23 defunciones, revascularización de vaso responsable $3.36 \%$, de otro vaso $39.5 \%$, reinfarto en $6.97 \%$, trombosis del stent en 1.23\%. La clase funcional: I en 140 (57.6\%), II en 44 (18.1\%), III (1.23\%). Clopidogrel durante $10.2 \pm 0.4$ meses. Discusión y conclusiones: La ICP primaria en adultos mayores tiene una tasa baja de complicaciones y mejor supervivencia, sobre todo realizada en centros con operadores con experiencia y con gran volumen de pacientes.

\subsection{Valvuloplastia con balón como puente a implante valvular transaórtico en un paciente con choque cardiogénico}

Rodríguez López Sergio Alberto, Martínez Jaimes Tomás, Hernández Germán Ricardo, Antezana Castro Javier, Millán Iturbide Oscar, Uribe González Jonathan, Estrada Gallegos Joel

Hospital de Cardiología del Centro Médico Nacional

Siglo XXI, Instituto Mexicano del Seguro Social.

Tipo de estudio: Estudio terapéutico

Introducción: La valvuloplastia aórtica con balón (VAB) tiene en la actualidad un nivel de evidencia II-b como puente a cirugía o implante valvular transaórtico (TAVI) por parte de la guía de manejo de valvulopatías 2017 de la Sociedad Europea de Cardiología, presentamos el caso de una paciente con choque cardiogénico

Figura 7.27.1.

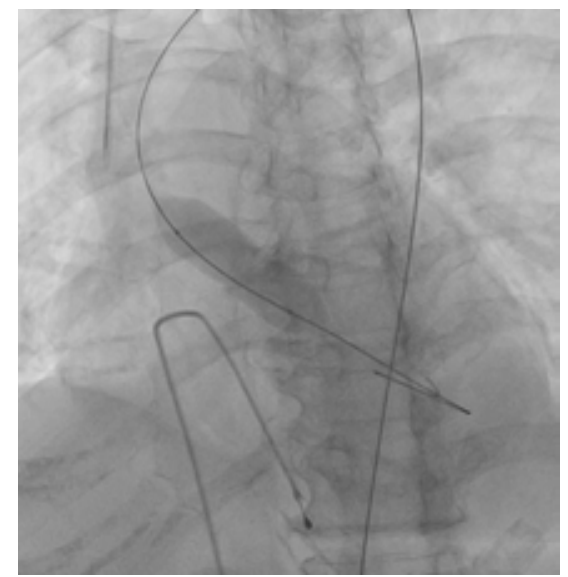

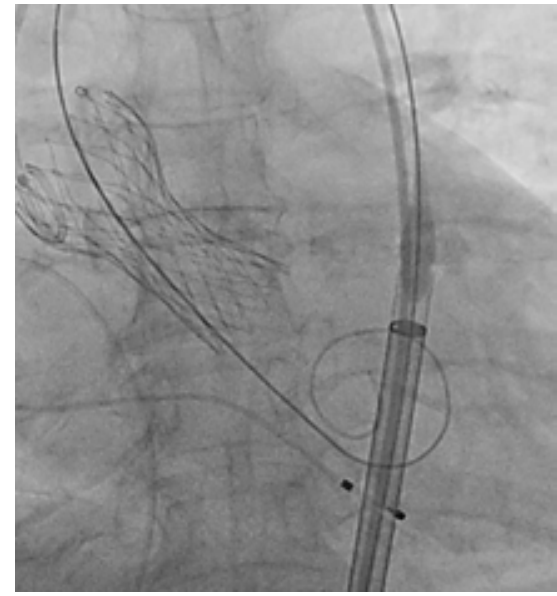

Figura 7.27.2.

secundario a estenosis aórtica severa. Descripción del caso: Femenino de 70 años, hospitalizada por antecedente de estenosis aórtica severa y descompensación, ecocardiograma transtorácico reporta válvula aórtica con calcificación severa, gradiente medio de $115 \mathrm{mmHg}$, área valvular aórtica por continuidad de $0.43 \mathrm{~cm}^{2}$, FEVI del 65\%. Coronariografía sin lesiones coronarias, gradiente pico-pico de $120 \mathrm{mmHg}$, sin insuficiencia aórtica. Durante su estancia la paciente presenta choque cardiogénico requiriendo apoyo vasopresor. Metodología: A través del método booleano se realizó búsqueda MeSH «Aortic-Valve-Stenosis» «TransaorticValve-Replacement» «Aortic Valve Ballon Valvotomy» en las bases de datos indizada (PubMed) y no indizadas (Google Scholar). La VAB se realiza en 16 a 25\% de pacientes con indicación de TAVI, con porcentaje de reestenosis anual mayor del 50\%, por lo cual la terapia destino no debe realizarse más allá de los siete meses. Resultados: Se procede a la realización de VAB, con balón ZMED de $18 \times 40 \mathrm{~mm}$ consiguiendo disminución del gradiente pico-pico en 44\%, con insuficiencia aórtica ligera. Posterior a su estancia en la Unidad de Cuidados Intensivos Coronarios, la paciente es retirada de ventilación mecánica y se retiran vasopresores, presentando condiciones óptimas para la realización de TAVI. Discusión y conclusiones: Se implanta válvula Core Valve Evolut Pro de $26 \mathrm{~mm}$, sin fuga paravalvular, con gradiente final de $3 \mathrm{mmHg}$. La paciente egresa a domicilio tras una corta recuperación en piso.

\subsection{Experiencia inicial del acceso transradial distal en angiografía coronaria e intervención coronaria}

Pimentel Morales Gela, Malváez López Héctor Miguel,

Estrada Gallegos Joel, Ramírez Koelliker Ramón, Arizmendi Uribe Efraín,

Saturno Chiu Guillermo

Centro Médico Nacional Siglo XXI, IMSS.

Tipo de estudio: Estudio terapéutico

Introducción: El acceso transradial distal (ATRd) para el cateterismo coronario ha surgido como una alternativa al clásico acceso transradial antebrazo con ciertas ventajas y limitaciones. Existe una falta de evidencia para el uso rutinario de ATRd en términos de éxito de punción, éxito de procedimiento, complicaciones relacionadas con el procedimiento y curva de aprendizaje. Objetivo: Evaluar la 
factibilidad y seguridad del ATRd como acceso predeterminado para la angiografía coronaria e ICP. Se evaluó patencia a 24 horas y las complicaciones. Metodología: Descripción de nuestra experiencia en el ATRd en 139 pacientes a los que se les realizó cateterismo cardiaco independientemente de la indicación y procedimiento. Resultados: Características basales: hombres 79\%, edad promedio $63.7 \pm 9.4$ años, enfermedad coronaria estable en $72.5 \%$, SICA $14.5 \%$, valvular $13 \%$, éxito en $94.8 \%$, tiempo de punción $1.67 \pm$ 2.3 minutos, acceso derecho $87 \%$, falla del acceso $5.7 \%$. Se realizó ICP en 33.8\%, de los cuales DA 65\%, Cx 15\%, CD 19\%. Tiempo de hemostasia $176 \pm 14.8 \mathrm{~min}$. Complicaciones: hematoma $2.8 \%$, espasmo $3.6 \%$, sin documentarse oclusión o perforación de la arteria radial, pseudoaneurisma o fístulas AV. Tiempo de fluoroscopia 7.2 $\pm 7.9 \mathrm{~min}$, contraste $121 \pm 87.3 \mathrm{~mL}$. Discusión y conclusiones: Reportamos una alta tasa de éxito y muy pocas complicaciones utilizando el ATRd, lo cual apoya a la factibilidad y seguridad durante la coronariografía e ICP documentado en otros centros.

\subsection{Desenlaces de los pacientes con IAMCEST complicados con choque cardiogénico sometidos a ICP}

Pimentel Morales Gela, Malváez López Héctor Miguel,

Estrada Gallegos Joel, Arizmendi Uribe Efraín, Mayorquín Carranza Javier, Saturno Chiu Guillermo

Centro Médico Nacional Siglo XXI, IMSS.

Tipo de estudio: Registros locales o nacionales

Introducción: En el contexto de pacientes con IAMCEST complicados con choque cardiogénico, la restauración de la perfusión miocárdica es parte esencial de las metas de tratamiento, por lo que tanto la ICP como el soporte circulatorio son prioritarios. Objetivo: Evaluar los desenlaces y el manejo de los pacientes con choque cardiogénico en el contexto de IAMCEST en nuestro hospital. Metodología: Se incluyeron al registro pacientes con IAMCEST complicados con choque cardiogénico, sometidos a ICP, atendidos en nuestro hospital. Resultados: Incluimos un total de 32 pacientes con IAMCEST complicados con choque cardiogénico, las características basales: 63.6\% fueron hombres, edad promedio de 66.1 años, DM2 68.7\%, hipercolesterolemia 40.6\%, HAS 65.6\%, tabaquismo $46.8 \%$, infartos previos $21.8 \%$; infarto anterior en $40.6 \%$, enfermedad multivaso en $50 \%$. Se realizó trombólisis previa a ICP en $37.5 \%$, se colocó BIAC en 25\%, tromboaspiración en $43.7 \%$, se colocaron un promedio de $1.1 \pm 0.3$ stents. Se documentó flujo final TIMI 3 en $62.5 \%$, la complicación más frecuente fue no flujo en $65.7 \%$, lesión renal aguda en $18.1 \%$. Hubo 59.9\% de mortalidad intrahospitalaria. Discusión y conclusiones: Los pacientes con IAMCEST complicados con choque cardiogénico continúan presentando alta mortalidad a pesar de las terapias actuales. Se requieren mejoras adicionales en el sistema de salud para mejorar desenlaces.

\subsection{IAMCEST en el paciente joven, características clínicas y angiográficas, desenlaces hospitalarios y a largo plazo}

Pimentel Morales Gela, Malváez López Héctor Miguel,

Estrada Gallegos Joel, Arizmendi Uribe Efraín, Mayorquín Carranza Javier, Saturno Chiu Guillermo

Centro Médico Nacional Siglo XXI, IMSS.

Tipo de estudio: Registros locales o nacionales
Introducción: La enfermedad arterial coronaria es la principal causa de mortalidad en México y se presenta con mayor frecuencia en sujetos de edad avanzada. La información sobre pacientes < 40 años con IAMCEST es escasa. Aunque es un problema menos frecuente puede constituir un obstáculo importante al tener efectos devastadores en la calidad de vida de estos pacientes. Objetivo: Describir las características basales de los pacientes < 45 años que se presentaron con IAMCEST a nuestro hospital y evaluar desenlaces hospitalarios y a largo plazo. Metodología: Se evaluaron un total de 27 pacientes menores de 45 años, quienes se presentaron a nuestro hospital con diagnóstico de IAMCEST entre enero de 2013 y enero de 2016. Resultados: Características basales: 88.8\% fueron hombres, edad $41 \pm 4.7$ años, DM2 33.3\%, hipercolesterolemia $44.4 \%$, HAS $40.7 \%$, obesidad $25.9 \%$, sólo uno con antecedente de infarto. Enfermedad multivaso 18.5\%, la DA afectada en $70.3 \%$. En $96.3 \%$ se realizó ICP primaria, en un paciente no fue posible por ectasia. Promedio de stents implantados $1.1 \pm 0.4$, tromboaspiración 55.5\%, FEVI > 50\%, uso de GPIIb/ IIla en $33.3 \%$, flujo final TIMI 3 en $85 \%$. Seguimiento a $32.8 \pm$ 8.4 meses. No se documentaron defunciones intrahospitalarias ni en el seguimiento. No hubo reinfartos ni rehospitalizaciones. El 85\% se mantuvo en CF I. Discusión y conclusiones: La coronariografía revela enfermedad menos extensa y frecuentemente de un solo vaso. Los desenlaces a corto y largo plazo son buenos, sin mortalidad, FEVI 50\%, CF I en $85 \%$.

\subsection{Manejo de los pacientes con IAMCEST y tecnologías actuales, seguimiento a largo plazo}

Pimentel Morales Gela, Malváez López Héctor Miguel,

Estrada Gallegos Joel, Arizmendi Uribe Efraín, Mayorquín Carranza Javier, Saturno Chiu Guillermo

Centro Médico Nacional Siglo XXI, IMSS.

Tipo de estudio: Registros locales o nacionales

Introducción: La angioplastia coronaria percutánea primaria (ICP) ha surgido como el método de elección para la revascularización de los pacientes con IAMCEST. Múltiples estudios aleatorizados y estudios clínicos han demostrado una mejoría en los desenlaces clínicos comparados con la reperfusión con medicamentos. Objetivo: Describir las características clínicas y demográficas de los pacientes sometidos a ICP como manejo de IAMCEST con las tecnologías actuales en nuestro hospital. Metodología: Se evaluó a un total de 451 pacientes de enero de 2013 a diciembre de 2015. El objetivo primario fue la combinación de mortalidad, infarto y revascularización a largo plazo. Resultados: Características basales: edad $64 \pm$ 11 años, 75.1\% fueron hombres, DM2 46.4\%, hipercolesterolemia $43.4 \%$, HAS $60.7 \%$, tabaquismo $62.5 \%$, infarto previo $10.6 \%$, ICP previa $7.1 \%$, CRVC previa 1.1\%, FEVI $48.5 \pm 10.7 \%$. Enfermedad multivaso en $32.5 \%$, infarto inferior $55.7 \%$. Trombólisis previa efectuada en $23.2 \%$, exitosa en $43 \%$. El acceso transradial se realizó en $67.3 \%$ y fue exitoso en $80.4 \%$. Se implantó DES en $89.3 \%$, en promedio $1.2 \pm 0.6$ stents, tromboaspiración 48.8\%, GPIIb/IIla en $26.5 \%$. El seguimiento fue de $31.7 \pm 9.3$ meses, con mortalidad de $9.5 \%$ (6.2\% de causa $\mathrm{CV}$ ), revascularización de vaso diana $0.5 \%$, reinfarto $19.5 \%$, TS 0.9\%, CF I (76.2\%). Discusión y conclusiones: Los datos en nuestro registro documentan buenos resultados para la ICP en IAMCEST, por lo que las nuevas tecnologías, técnicas y tratamientos deben ser promovidos. 


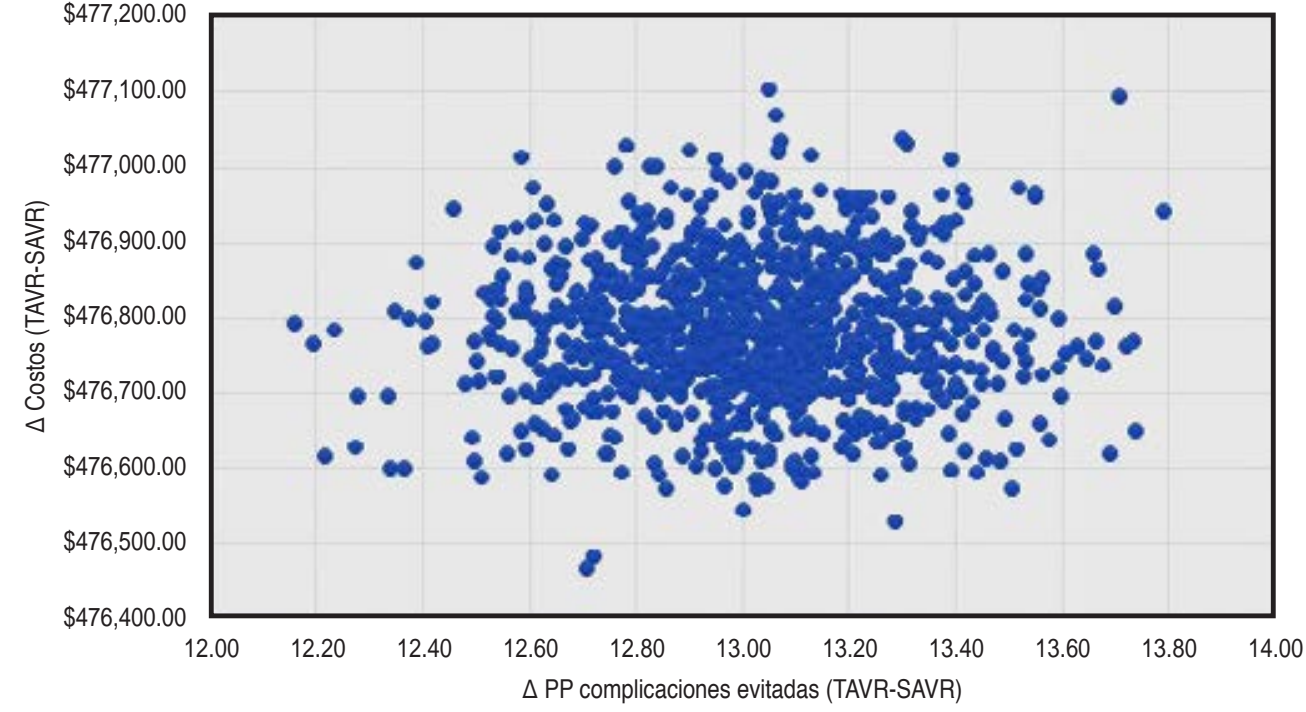

Figura 7.32.1:

El análisis de sensibilidad probabilística muestra que al elaborar la simulación sobre 1,000 pacientes, la razón costo-efectividad incremental presenta un intervalo de confianza al 95\% de 36,611 a 36,700 pesos por cada punto porcentual adicional de complicaciones evitadas. $P P=$ puntos porcentuales.

Tabla 7.32.1: Características clínicas, ecocardiográficas y desenlaces intrahospitalario de acuerdo con tipo de procedimiento.

\begin{tabular}{|c|c|c|c|}
\hline & TAVR $(n=22)$ & SAVR $(n=64)$ & $\mathbf{p}$ \\
\hline Edad (años) & $77 \pm 7$ & $73 \pm 6$ & 0.009 \\
\hline \multicolumn{4}{|l|}{ Género } \\
\hline Masculino & $1(5)$ & 38 (59) & 0.0001 \\
\hline Femenino & $21(95)$ & $26(41)$ & 0.0001 \\
\hline Diabetes mellitus (\%) & $3(14)$ & $29(45)$ & 0.008 \\
\hline Hipertensión arterial (\%) & $16(73)$ & $51(80)$ & 0.49 \\
\hline Cardiopatía isquémica (\%) & $4(18)$ & - & 0.0005 \\
\hline STS PROM (riesgo) & $7(7-8)$ & $6(6-7)$ & 0.0001 \\
\hline Área valvular pre $\left(\mathrm{cm}^{2}\right)$ & $0.56(0.45-0.72)$ & $0.5(0.4-0.6)$ & 0.07 \\
\hline Gradiente pre (mmHg) & $51(42-64)$ & $50(46-55)$ & 0.55 \\
\hline Área valvular post $\left(\mathrm{cm}^{2}\right)$ & $1.75(1.4-1.9)$ & $1.2(1.1-1.3)$ & $<0.0001$ \\
\hline Gradiente post (mmHg) & $10.5(8-17)$ & $20(19-22)$ & $<0.0001$ \\
\hline Mortalidad (\%) & $2(9)$ & - & 0.014 \\
\hline Días de estancia intrahospitalaria & $5(4-6)$ & $11(10-13)$ & 0.0001 \\
\hline Días estancia cuidados intensivos & $2 \pm 0.68$ & $6 \pm 3.0$ & 0.0001 \\
\hline Días estancia en piso hospitalización & $3 \pm 1.50$ & $6 \pm 1.5$ & 0.0001 \\
\hline Días de intubación & $0(0-1)$ & $1(1-2)$ & 0.0001 \\
\hline Uso aminas vasoactivas & $6(27)$ & $63(98 \%)$ & 0.0001 \\
\hline Días uso aminas vasoactivas & $0.27 \pm 0.45$ & $1.6 \pm 0.78$ & 0.0001 \\
\hline Hemorragia mayor & $2(9)$ & $14(22)$ & 0.18 \\
\hline Evento vascular cerebral & - & - & - \\
\hline Sepsis (\%) & $2(9)$ & $22(34)$ & 0.02 \\
\hline Uso antibiótico (\%) & $3(14)$ & $23(36)$ & 0.05 \\
\hline Días antibiótico & $0.63 \pm 1.6$ & $3 \pm 4$ & 0.0005 \\
\hline Colocación marcapaso definitivo (\%) & $3(14)$ & $1(2)$ & 0.02 \\
\hline Uso de terapia reemplazo renal & - & $2(3)$ & 0.40 \\
\hline Infarto del miocardio & - & - & - \\
\hline Choque (\%) & $2(9)$ & $8(13)$ & 0.66 \\
\hline Endocarditis & - & - & - \\
\hline Reintervención & - & $6(9)$ & 0.14 \\
\hline Complicaciones vasculares & - & - & - \\
\hline Objetivos compuesto de efectividad (MACE) (\%) & $7(32)$ & $29(45)$ & 0.26 \\
\hline
\end{tabular}

MACE = evento cardiovascular mayor. 


\subsection{Costo-efectividad del reemplazo transcatéter vs quirúrgico en EAo severa de riesgo intermedio $y$ alto}

García Méndez Rosalba Carolina, Jaimes Martínez Tomás De Jesús, Lupercio Mora Karina, Estrada Gallegos Joel, Zavala Landín José Alejandro, Zamudio López Jonathan Omar, Saturno Chiu Guillermo

UMAE Hospital de Cardiología del Centro

Médico Nacional Siglo XXI, IMSS.

Tipo de estudio: Estudio pronóstico

Introducción: El reemplazo valvular aórtico transcatéter (TAVR) es seguro y eficaz en estenosis aórtica (EAo) severa en pacientes inoperables, no inferior vs reemplazo valvular quirúrgico (SAVR) para mortalidad y presentación de EVC en riesgo intermedio-alto. Estudios internacionales han evaluado el impacto económico en el mundo real. Existe vacío en el conocimiento de México, IMSS y nuestro centro. Objetivo: Comparar costo-efectividad del reemplazo valvular transcatéter (TAVR) vs quirúrgico (SAVR) en EAo severa sintomática de riesgo intermedio-alto mediante desenlace compuesto intrahospitalario (MACE): muerte, hemorragia, marcapaso definitivo, EVC y sepsis. Metodología: Estudiamos a pacientes de 18 a 90 años, con EAo severa sintomática, STSPROM intermedio-alto sometidos a TAVR vs SAVR. Excluimos dos o más

Tabla 7.32.2: Resultados del análisis de sensibilidad de acuerdo con tipo de procedimiento.

\begin{tabular}{|lcccc|} 
& TAVR & SAVR & & \\
\hline Costos, \$ & 855,475 & 378,688 & CI 476,786 & RCEI 36,674 \\
Efectividad (\%) & 68 & 55 & EI 13 & \\
& 0.557 & 55.7 & 4.2 & \\
& & & &
\end{tabular}

TAVR = reemplazo valvular aórtico transcatéter, SAVR = reemplazo valvular aórtico quirúrgico; $\mathrm{CI}$ = costo incremental; RCEI = razón costo efectividad incremental; EI = efectividad incremental. TAVR es $55.7 \%$ más caro (Mx $\$ 476,785$ pesos adicionales) y más efectivo (13\% mayor) que SAVR.

Los resultados muestran que la razón costo efectividad incremental es de \$36,674 pesos por cada punto porcentual adicional de complicaciones evitadas. Dicho de otra forma, por cada 4.2 puntos porcentuales adicionales gastados, la TAVR aumenta en un punto porcentual en complicaciones evitadas. valvulopatías, cirugía valvular aórtica o revascularizaciones previas, coronariopatía susceptible de revascularización. Tratamiento establecido por equipo de expertos. Evaluación económica completa: costos directos, días promedio de estancia, complicaciones intrahospitalarias, razón costo-efectividad incremental (RCEI) y análisis de sensibilidad. Resultados: Ochenta y seis pacientes, tres controles quirúrgicos para control de confusores; 22 TAVR y 64 SAVR. Diferencias respectivas: edad $77.7 \pm 7$ vs $73 \pm 6$ años $(p \leq$ $0.009)$; sexo femenino (95\%) TAVR vs (41\%) SAVR ( $\leq 0.0001)$; cardiopatía isquémica 18 vs $0 \%(p \leq 0005)$; STS-PROM 7 (7-8) vs $6(6-7)$ ( $p \leq 0001)$; gradiente postprocedimiento 10.5 (8-17 $\mathrm{mmHg})$ vs $20(19-22 \mathrm{mmHg})(\mathrm{p} \leq 0001)$; MACE 7 (32\%) vs 29 $(45 \%)(p=0.26)$. Costos y efectividad con complicaciones TAVR vs SAVR: $\$ 855,475$ vs $\$ 378,688$ y 68 vs $55 \%$. RCEI $\$ 36,674$ por cada punto porcentual de complicaciones evitadas. Discusión y conclusiones: El análisis económico realizado mostró que TAVR constituye un procedimiento costo-efectivo respecto a SAVR de acuerdo a la RCEI obtenida por cada punto porcentual de complicación evitada del desenlace compuesto.

\subsection{Cierre de fuga paravalvular aórtica vía retrógrada, una alternativa viable}

Conrado Hernández Iván, Bazzoni Ruiz Alberto Esteban Instituto Mexicano del Seguro Social.

Tipo de estudio: Reporte de casos clínicos con revisión de fuentes

Introducción: El cierre percutáneo ha mostrado resultados de éxito de hasta $86 \%$, sobre todo en pacientes con alto riesgo en reparación o sustitución quirúrgica. Actualmente, en nuestro nosocomio hemos implementado el tratamiento percutáneo de la fuga paravalvular, con apoyo de múltiples modalidades de imagen, como la fusión de imagen, que ha ayudado a guiar el procedimiento. Descripción del caso: Paciente masculino de 59 años, diagnosticado en 2008 con estenosis aórtica. Se realizó cirugía de reemplazo valvular aórtico el 28/11/2018, posterior al evento quirúrgico presentó datos de falla cardiaca, el ecocardiograma transtorácico mostró fuga paravalvular, por lo que es reintervenido en febrero de 2019. En el seguimiento presentó anemia hemolítica, fue revalorado, se encontró fuga paravalvular anterior, por lo que se propuso para cierre percutáneo. Metodología: Previo a su internamiento el paciente negó síntomas o exposiciones de riesgo de COVID-19, como parte del protocolo se realizó detección de PCR SARS-CoV-2 siendo positiva. Se efectuó
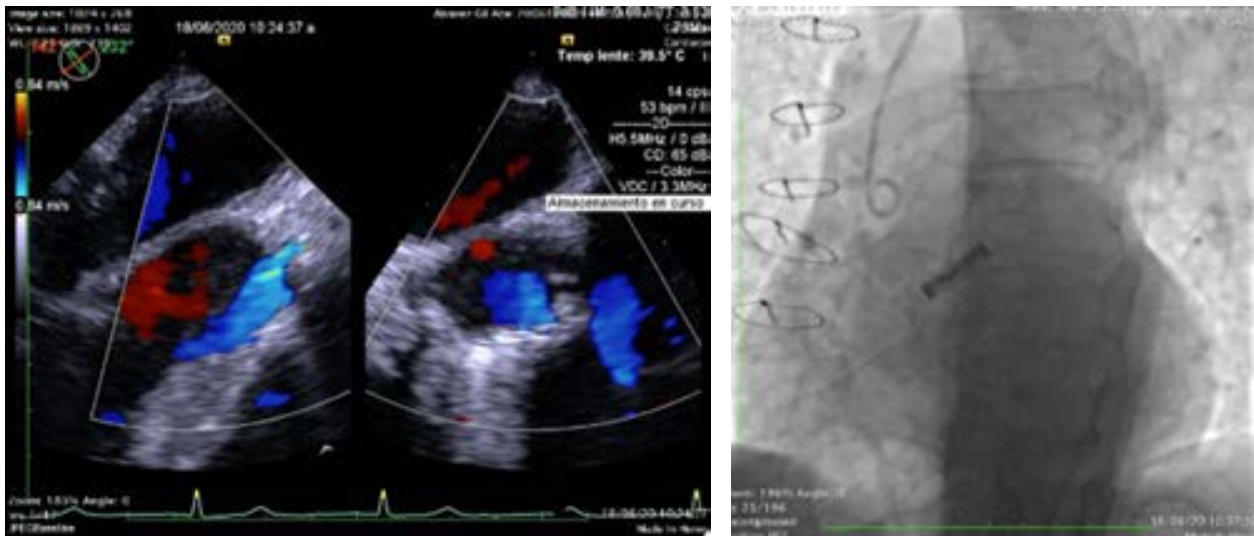

Figura 7.33.1:

Fuga paravalvular aórtica, a la izquierda en ecocardiograma transesofágico Doppler color, a la derecha aortograma. 
Figura 7.33.2:

Aortograma con dispositivo

en entrega en

posición, se corrobora oclusión

del defecto.

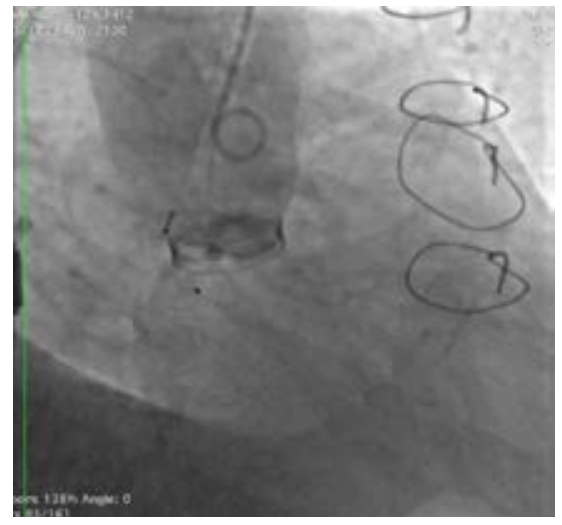

abordaje femoral arterial y se entregó dispositivo AVP II de $6 \mathrm{~mm}$, se realizó control fluoroscópico, con fuga de medio de contraste trivial, en imagen ecocardiograma con dispositivo en posición y fuga trivial. Resultados: El paciente tuvo una evolución clínica favorable, posterior a 48 horas de observación y permaneciendo aislado por riesgo de diseminación del virus SARS-CoV-2 es egresado sin eventualidades. En consulta de seguimiento posterior a un mes de

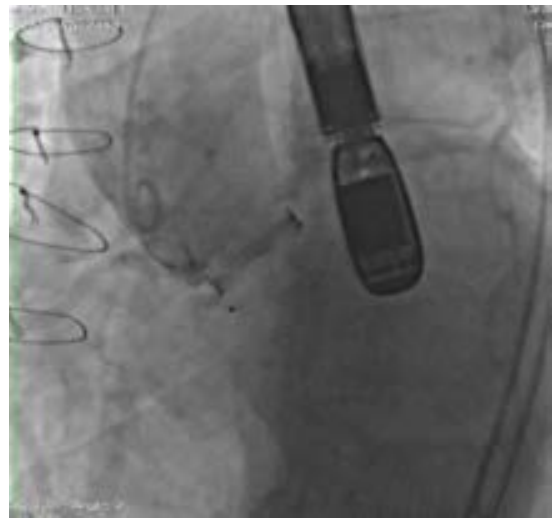

Figura 7.33.3:

Aortograma con dispositivo AVP II de $6 \mathrm{~mm}$ en posición, se evidencia fuga anterior trivial.

evolución se encuentra en clase funcional I y sin datos de anemia. Discusión: El cierre percutáneo es una opción real en nuestro medio, con resultados satisfactorios y bajo riesgo periprocedimiento. Consideramos que todos los pacientes sometidos de manera electiva a intervencionismo deben ser cribados con pruebas para descartar infección activa de COVID-19, ya que una gran proporción de pacientes serán portadores asintomáticos. 